\title{
Catalytic Technologies for CO Hydrogenation for the Production of Light Hydrocarbons and Middle Distillates
}

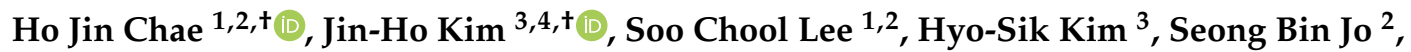 \\ Jae-Hong Ryu ${ }^{3}$, Tae Young Kim ${ }^{2}$, Chul Ho Lee ${ }^{2}$, Se Jeong Kim ${ }^{2}$, Suk-Hwan Kang ${ }^{3, *}$, \\ Jae Chang Kim ${ }^{2, *}$ and Myung-June Park ${ }^{4,5, * \text { D }}$ \\ 1 Research Institute of Advanced Energy Technology, Kyungpook National University, Daegu 41566, Korea; \\ hwman777@nate.com (H.J.C.); soochool@knu.ac.kr (S.C.L.) \\ 2 Department of Chemical Engineering, Kyungpook National University, Daegu 41566, Korea; \\ santebin@knu.ac.kr (S.B.J.); tyoung0218@knu.ac.kr (T.Y.K.); cjfgh38@knu.ac.kr (C.H.L.); \\ sjkim@knu.ac.kr (S.J.K.) \\ 3 Plant Engineering Center, Institute for Advances Engineering (IAE), Yongin-si, Gyeonggi-do 17180, Korea; \\ jinho@iae.re.kr (J.-H.K.); hyosgogo@iae.re.kr (H.-S.K.); jhryu@iae.re.kr (J.-H.R.) \\ 4 Department of Chemical Engineering, Ajou University, Suwon-si, Gyeonggi-do 16499, Korea \\ 5 Department of Energy Systems Research, Ajou University, Suwon-si, Gyeonggi-do 16499, Korea \\ * Correspondence: shkang@iae.re.kr (S.-H.K.); kjchang@knu.ac.kr (J.C.K.); mjpark@ajou.ac.kr (M.-J.P.); \\ Tel./Fax: +82-31-330-7880/7850 (S.-H.K.); +82-53-950-5622/6615 (J.C.K.); +82-31-219-2895/1612 (M.-J.P.) \\ + These authors contribute equally to this work.
}

Received: 2 December 2019; Accepted: 7 January 2020; Published: 9 January 2020

\begin{abstract}
In South Korea, where there are no resources such as natural gas or crude oil, research on alternative fuels has been actively conducted since the 1990s. The research on synthetic oil is subdivided into Coal to Liquid (CTL), Gas to Liquid (GTL), Biomass to Liquid (BTL), etc., and was developed with the focus on catalysts, their preparation, reactor types, and operation technologies according to the product to be obtained. In Fischer-Tropsch synthesis for synthetic oil from syngas, stability, CO conversion rate, and product selectivity of catalysts depends on the design of their components, such as their active material, promoter, and support. Most of the developed catalysts were Fe- and Co-based catalysts and were developed in spherical and cylindrical shapes according to the reactor type. Recently, hybrid catalysts in combination with cracking catalysts were developed to control the distribution of the product. In this review, we survey recent studies related to the design of catalysts for production of light hydrocarbons and middle distillates, including hybrid catalysts, encapsulated core-shell catalysts, catalysts with active materials with well-organized sizes and shapes, and catalysts with shape- and size-controlled supports. Finally, we introduce recent research and development (R\&D) trends in the production of light hydrocarbons and middle distillates and in the catalytic processes being applied to the development of catalysts in Korea.
\end{abstract}

Keywords: syngas; Fischer-Tropsch; catalyst design; active metal size; acidic site control; hydrocarbons

\section{Introduction}

The production of hydrocarbons, alcohols, and dimethyl ether (DME), which are alternative fuels, from syngas has been reported by numerous researchers; some of these methods are currently being developed, and some are being conducted at commercial scale. As shown in Figure 1, the conversion of syngas to alternative fuels can produce methanol, DME, or hydrogen; the syngas can be obtained by methanation or Fischer-Tropsch (FT) reaction from methane-containing hydrocarbons. 
Following the energy crisis of the 1970s, the Fischer-Tropsch synthesis (FTS) reaction attracted increased because of the high cost of oil [1]. Since 1995, the FTS reaction has been attracting further attention, as shown in Figure 2. This attention not only reflects oil prices but also the demand for energy security, demassification of energy sources, and sulfur-free or NOx-free resources to protect the environment [2]. The FTS reaction is one of the reactions for growing carbon chains $\left(-\mathrm{CH}_{2}-\right)$ to produce hydrocarbons of various lengths (paraffins or olefins). Representative catalysts for this purpose mainly consist of $\mathrm{Fe}$ and/or Co as the active material. Fe-based catalysts are relatively inexpensive and have a wide range of operating temperatures, which is advantageousness for producing olefins, gasoline, or diesel fuel. Although the Co-based catalysts have a narrow operating temperature range of $220-240{ }^{\circ} \mathrm{C}$, their paraffin wax productivity is superior to that of the Fe-based catalysts [3].

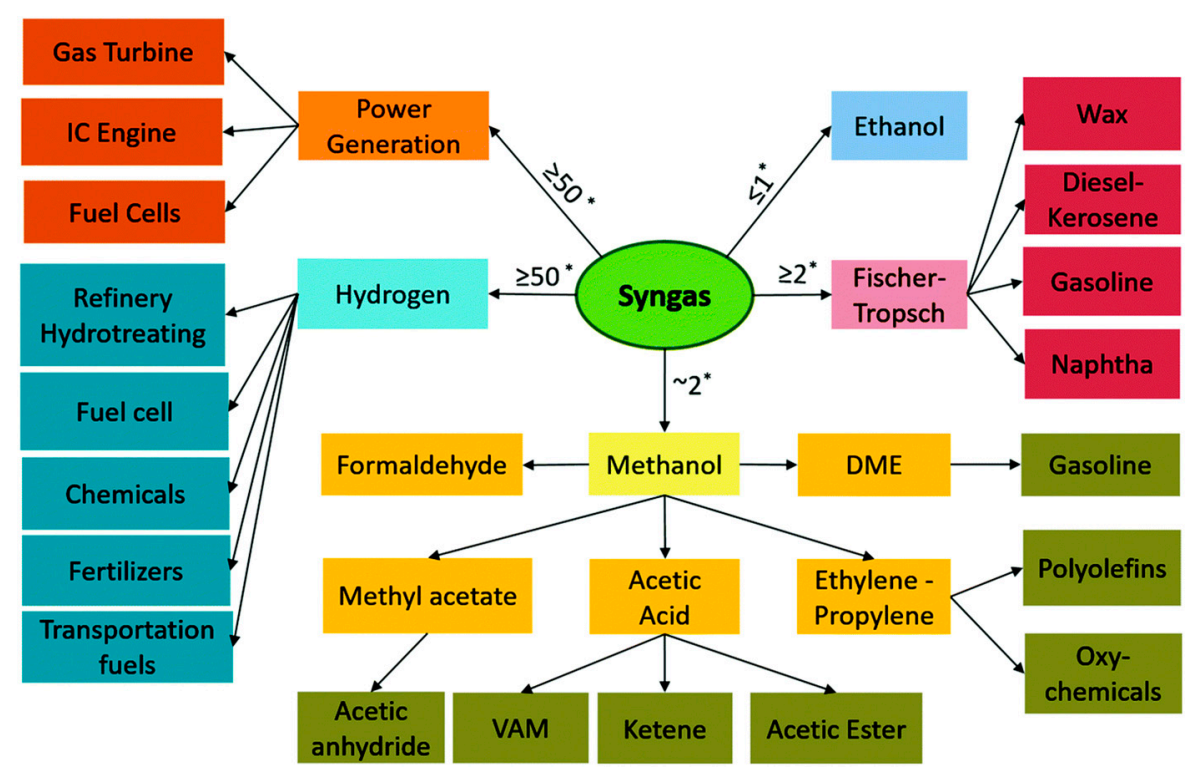

Figure 1. Application of syngas $\left({ }^{*} \mathrm{H}_{2} / \mathrm{CO}\right.$ ratio). Reprinted with permission from [1]. Copyright (2017) Royal Society of Chemistry (RSC), Cambridge, England.

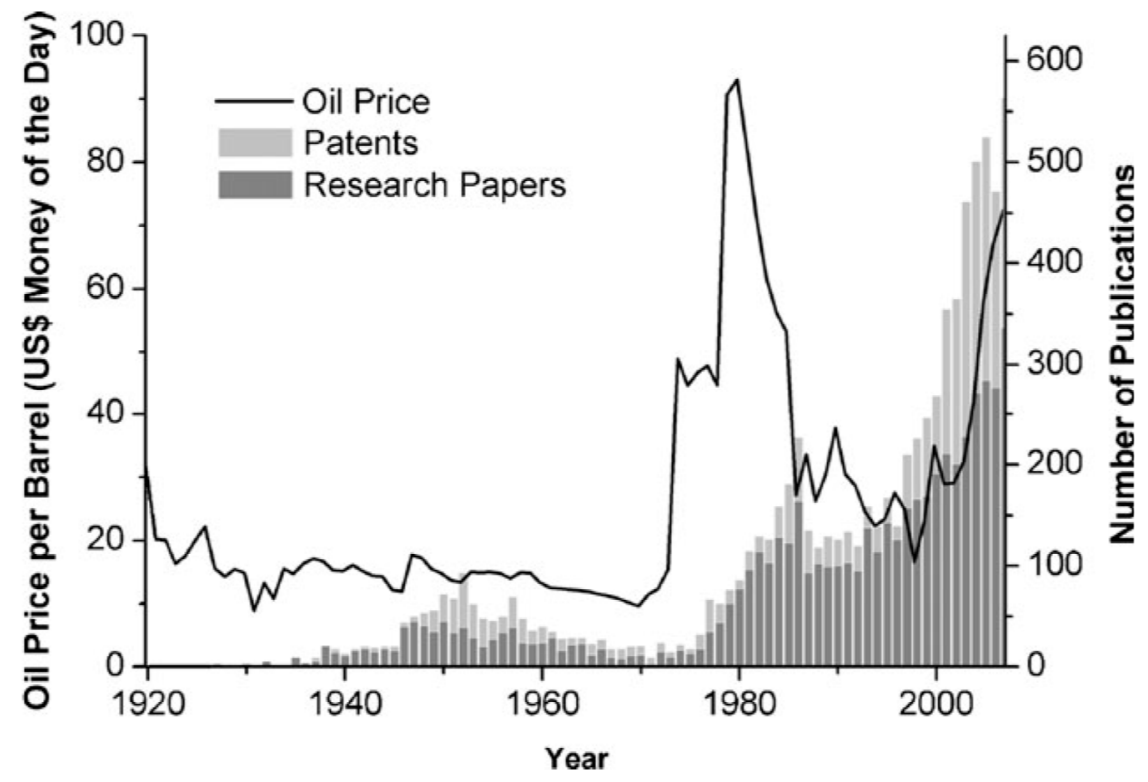

Figure 2. Oil price (line) related to the output of peer reviewed Fischer-Tropsch synthesis (FTS) research papers and patents4 (bars) in 1925-2007. Reprinted with permission from [2]. Copyright (2008) RSC, Cambridge, England. 
These FTS catalysts can be used to synthesize light hydrocarbons (with five or fewer carbon atoms), middle distillates (with 13 to 22 carbon atoms), and waxes (with 22 or more carbon atoms). The produced wax can again be used to obtain gasoline or diesel fuel through the cracking process. However, many wax products require additional processing. Thus, numerous studies have been conducted to improve the yield of light hydrocarbons or middle distillates and especially to increase the synthesis rate of $\mathrm{C}_{2}-\mathrm{C}_{12}$ by reducing the production ratio of $\mathrm{C}_{1}, \mathrm{CO}_{2}$, and $\mathrm{C}_{22+}$.

Nowadays, there are many kinds of research and works related to the FTS reaction due to the desire for energy transformation related to the hydrogen energy source and for the production of high valuable hydrocarbon worldwide. Additionally, many other researchers have reported review papers concentrated on these perspectives. However, in Korea, where fossil fuel resources such as natural gas and crude oil are not available, research on Coal to Liquid (CTL), Gas to Liquid (GTL), and Biomass to Liquid (BTL) began in the early 1990s to obtain alternative fuels. The Korea Research Institute of Chemical Technology (KRICT) reported a 10 Barrels Per Day (BPD) scaled GTL process that consists of the slurry bobble column reactor (SBCR) using Co-based catalysts from their research and development (R\&D) project between 2006 and 2015. The Korea Institute of Energy Research (KIER) reported a 15 BPD scaled CTL process that consists of the SBCR using Fe-based catalysts from their $R \& D$ project between 2005 and 2011. However, recently, there have been different approaches due to the difference in legal standards for domestic pipeline networks (natural gas) in South Korea and Japan from those in the USA and Europe (e.g., the calorific value of natural gas is higher, and methane composition is lower than those of the USA and Europe). However, the calorific value of the imported liquefied natural gas (LNG) is decreasing year by year because the exporting countries are extracting high calorific gases from LNG in order to sell it separately. Thus, the imported LNG should be adjusted by adding high calorific gases such as liquefied petroleum gas (LPG). Besides, the synthetic natural gas (SNG) (catalytic methanation process from synthetic gases) process was installed to replace natural gas energy security in Gwangyang. However, more than the LNG, the SNG product, which consists of over $95 \%$ of methane $\left(\sim 9300 \mathrm{kcal} / \mathrm{Nm}^{3}\right)$, should be adjusted. Thus, the need of high calorific gases (e.g., $\mathrm{C}_{2}-\mathrm{C}_{4}$ ) or high calorific SNG increased. From these perspectives, we introduce the typical FTS catalyst design approaches in South Korea against worldwide approaches.

This review is divided into five sections. The first section is the introduction. We introduce the FTS mechanism and the typical catalyst design technologies, along with catalyst components such as active materials, promoters, and support materials, in Section 2. In Section 3, we survey some recent approaches to achieving greater selectivity of the desired products. Section 4 is a discussion of the state-of-the-art catalyst technologies for the production of light hydrocarbons and middle distillates in South Korea. Finally, the implications, the challenges, and the research areas to be addressed for the commercialization of these catalytic technologies are discussed in the conclusion in Section 5.

\section{FTS Catalysts Design}

\subsection{Mechanism of Fischer-Tropsch Synthesis}

After a patent was granted to BASF (Global Company based on Germany) for a hydrocarbon production process using a Co catalyst, Fischer and Tropsch reported a hydrocarbon synthesis process capable of producing various organic compounds (e.g., ethane, propane, butane, octane, nonane, and iso-nonane) using alkali-iron catalysts under conditions of $400-450{ }^{\circ} \mathrm{C}$ and $100-150 \mathrm{~atm}$. In the early stage, the product was named "Synthol" and was not found to contain hydrocarbons. However, further studies revealed that the $\mathrm{Fe}-\mathrm{Co}$ catalyst could be used to produce hydrocarbons; these reactions are referred to as the FTS reaction.

For the general FTS, the reaction to produce alkanes (Equation (1)) and alkenes (Equation (2)) and schematics of the chain growth processes during the FTS reaction are shown as follows:

$$
\text { Paraffins: } \mathrm{nCO}+(2 \mathrm{n}+1) \mathrm{H}_{2} \rightarrow \mathrm{C}_{\mathrm{n}} \mathrm{H}_{2 \mathrm{n}+2}+\mathrm{nH}_{2} \mathrm{O}
$$




$$
\text { Olefins: } \mathrm{nCO}+2_{\mathrm{n}} \mathrm{H}_{2} \rightarrow \mathrm{C}_{\mathrm{n}} \mathrm{H}_{2 \mathrm{n}}+\mathrm{nH}_{2} \mathrm{O}
$$

Figure 3 shows the mechanism in the FTS reaction $[4,5]$. The first carbide mechanism on the iron catalyst involved the formation and the hydrogenation of metal carbides to give methylene groups on the surface of the metal, and the second oxygenate (enol) mechanism proposes chain growth by the non-dissociative chemisorption of $\mathrm{CO}$. The third $\mathrm{CO}$ insertion mechanism involves the insertion of $\mathrm{CO}$ into a metal-methyl or metal-methylene carbon bond, which is hydrogenated to produce an alcohol or alkene. Finally, the fourth alkenyl mechanism suggests that polymer chain carriers are surface alkenyl rather than alkyl species.

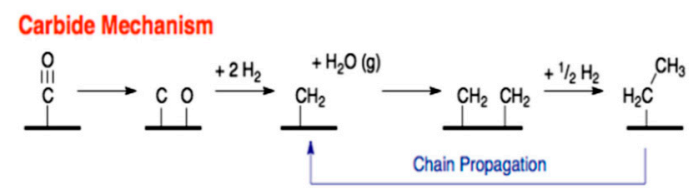

Oxygenate (enol) Mechanism

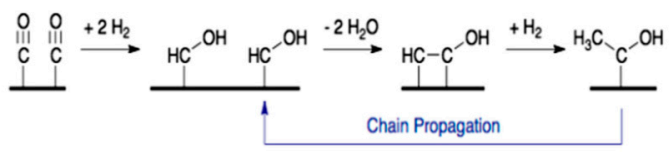

CO Insertion Mechanism

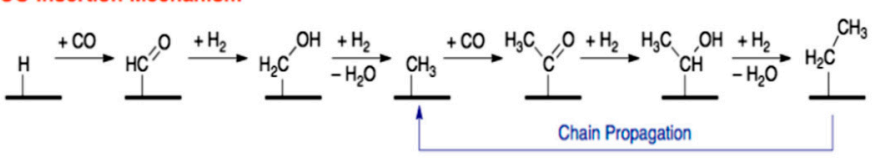

(a)

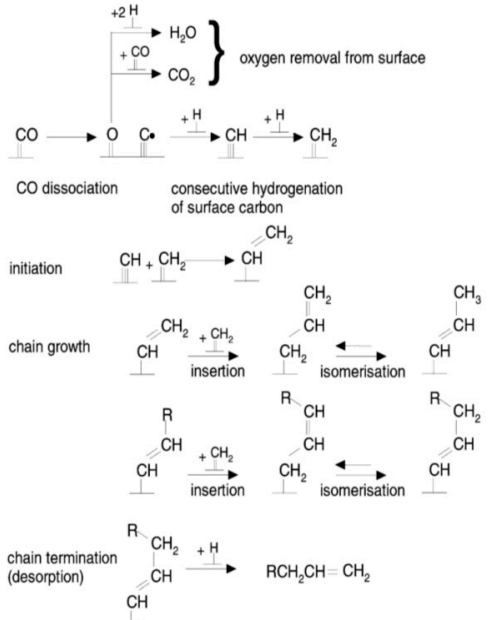

(b)

Figure 3. Schematics of chain growth in FTS. (a) Carbide, enol, and CO insertion mechanism; (b) alkenyl mechanism. Reprinted with permission from [4,5]. Copyright (2015) Academic Press Inc. Elsevier Science, San Diego, CA, America.

However, the Anderson-Schulz-Flory (ASF) model represents the ideal product distributions as a function of the chain-growth probability factor $\alpha$ [6]. The basic mathematical expression from the ASF model is as follows:

$$
\begin{gathered}
\ln \frac{W_{n}}{n}=n \ln \alpha+2 \ln \left(\frac{1-\alpha}{\sqrt{\alpha}}\right) \\
\alpha=\frac{R_{P}}{R_{P}+R_{t}}
\end{gathered}
$$

where $\alpha$ is the chain-growth probability factor, $R_{p}$ and $R_{t}$ are the rates of propagation and termination, respectively, and $W_{n}$ represents the mass fraction for the hydrocarbon with carbon number $n$. In the ASF model, the maximum selectivity of the desired products depends only on the chain-growth probability $(\alpha)$. However, some experiments have shown results that differ from those predicted by the ASF model (Figure 4) [7]. Therefore, one of the most challenging objectives in the field of FTS is the development of efficient catalysts that can control the distribution rather than providing the ASF distribution. Numerous other improved models have been developed; however, no pure light hydrocarbons or middle distillates have been obtained without purification steps. 


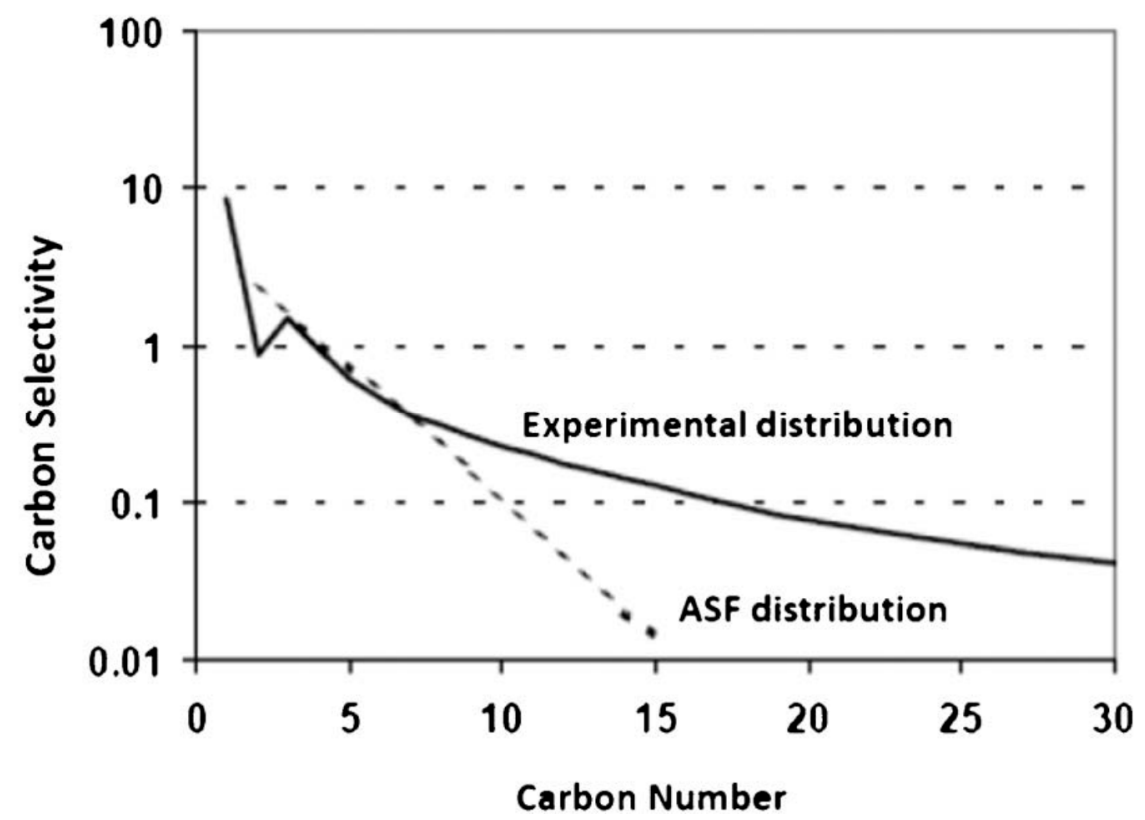

Figure 4. Experimental FTS product distribution in comparison to Anderson-Schulz-Flory (ASF).

Reprinted with permission from [7]. Copyright (2012) RSC, Cambridge, England.

In general, syngas with certain $\mathrm{H}_{2} / \mathrm{CO}$ ratios $(0.7-2.0)$ is known to generate hydrocarbons through repetitive and continuous (1) reactant adsorption/dissociation; (2) chain initiation; (3) chain growth; (4) chain termination; (5) product desorption; and (6) re-adsorption and further reaction steps at the surface of the metal (active component: $\mathrm{Fe}, \mathrm{Co}, \mathrm{Ru}, \mathrm{Ni}$, etc.).

Fischer and Tropsch suggested a carbide mechanism that the carbides formed by syngas generates a methylene group through the hydrogenation [8]. Especially in the case of the Fe-based catalysts, the phase of the active materials under FTS conditions during the activation step is changed, as shown in Figure 5; this change affects the catalytic activity. Fischer and Tropsch showed that the active phase of the Fe-based catalyst for the FTS reaction was not the catalyst metal surfaces but the formation of $\mathrm{Fe}-\mathrm{C}$ (Fe carbide). Light olefins $\left(\mathrm{C}_{2}=\right.$ to $\left.\mathrm{C}_{4}=\right)$ are directly produced from syngas as ethylene, propylene, butylene, etc. The maximum value of light hydrocarbons $\left(C_{2}-C_{4}\right)$ containing olefins was $56.7 \%$, the content of methane was $29.2 \%$, and the others were $\mathrm{C}_{5}{ }^{+}$[9].

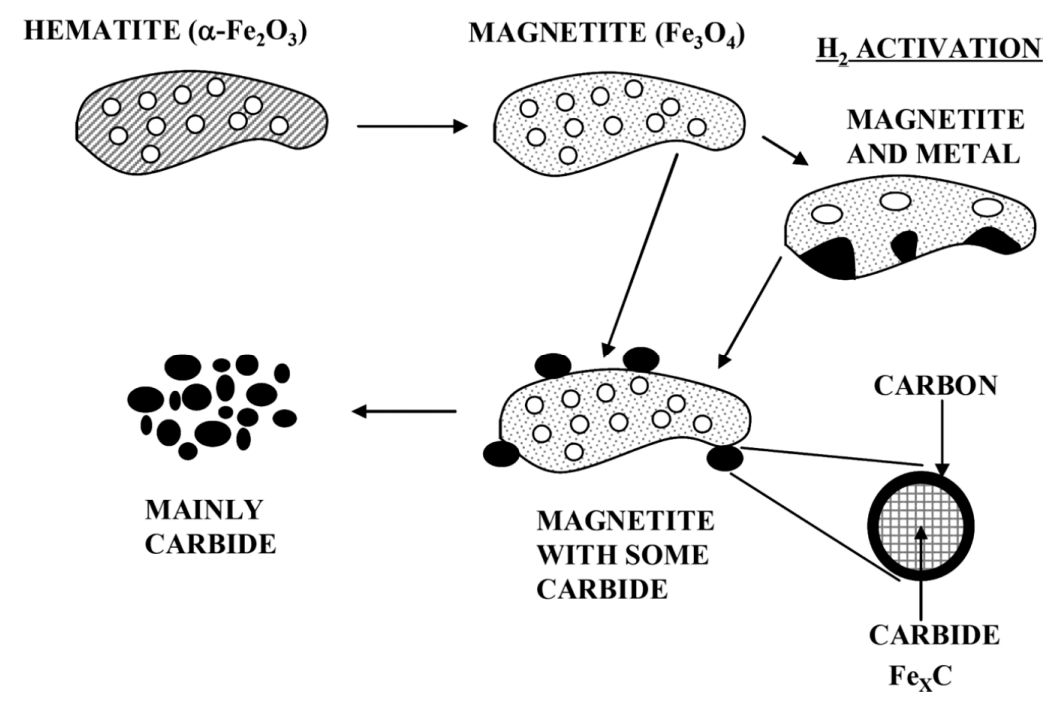

Figure 5. Schematic of morphological and phase changes that occur on the $\alpha-\mathrm{Fe}_{2} \mathrm{O}_{3}$ catalyst as a result of activation and reaction conditions [8]. 


\subsection{Active Materials}

Active materials such as $\mathrm{Co}, \mathrm{Fe}, \mathrm{Ru}$, and $\mathrm{Pt}$ can produce light hydrocarbons and middle distillates from syngas. The catalysts for these purposes consist of the active material, a promoter, and a support that enhances the mechanical strength of the catalyst and the size distribution of the active material. To achieve high catalytic performance (conversion, selectivity, and stability), chemical-physical properties (e.g., porosity, acidity, shape and size, composition, and density) and mechanical properties (e.g., physical strength and attrition) should be considered [10].

According to various literature reviews [11-14], the transition metals are a substantial component of the active materials of FTS catalysts. However, $\mathrm{Fe}, \mathrm{Co}, \mathrm{Ni}$, and $\mathrm{Ru}$ metals are acceptable catalysts for the FTS because of the dissociative adsorption ability of CO (Figure 6). Abundant literature indicates that the best active material for low-temperature FTS is $\mathrm{Ru}$. Since $\mathrm{Ru}$ is relatively expensive compared to $\mathrm{Fe}, \mathrm{Co}$, and $\mathrm{Ni}$, many studies have been conducted to design catalysts by maximizing dispersion in small amounts. Ni is a material with high hydrogenation activity, but its activity toward the methanation reaction is excessively high. Thus, $\mathrm{Co}$ and Fe are the most suitable transition-metal catalysts for the FTS reaction [15]. Fe is relatively inexpensive, exhibits a relatively wide operating temperature range, and demonstrates good olefin selectivity [16]. Co is relatively inexpensive and has a narrow operating temperature range from 220 to $240{ }^{\circ} \mathrm{C}$; it is preferred for the production of long-chain paraffin hydrocarbons.

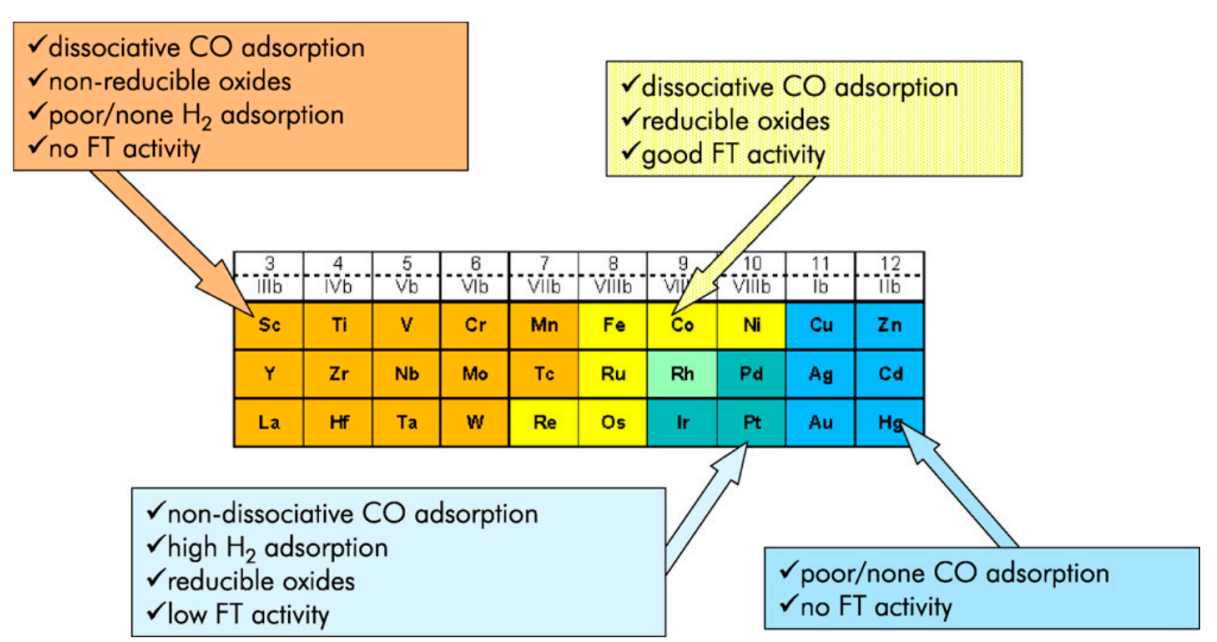

Figure 6. Behavior of transition metals towards the FTS reaction. Reprinted with permission from [12]. Copyright (2009) Elsevier Science BV, Amsterdam, The Netherlands.

\subsection{Promoters}

In general, in the field of heterogeneous catalysis, a small number of promoters are known to improve the catalytic activity and selectivity by enhancing physical and chemical properties of catalysts. FTS catalytic performance can be improved by adding a small amount of promoter that can substantially enhance the reducibility of $\mathrm{Co}$ and Fe. The literature contains numerous reports of certain metal oxides, alkali metals, and transition metals improving the FTS activities of transition metal catalysts. A promoter of Co-based catalysts could be Pd, Pt, Re, or Ru of $0.1-0.5 \%$ for selectivity and activity and 1-3\% rare-earth oxides, e.g., $\mathrm{ZrO}_{2}, \mathrm{La}_{2} \mathrm{O}_{3}$, or $\mathrm{ThO}_{2}$, for catalytic stability. However, Fe-based catalysts are typically promoted with copper to improve reducibility and with an alkali (preferably K) or Mn for selectivity and stability [17-42]. Feyzi et al. reported the effects of promoters on the FTS catalytic performance using iron-manganese catalysts at the ratio of $\mathrm{H}_{2} / \mathrm{CO}=2$, gas hourly space velocity $(\mathrm{GHSV})=1200 \mathrm{~h}^{-1}$, the pressure $=1 \mathrm{~atm}$ and reaction temperature $=250{ }^{\circ} \mathrm{C}$ condition . The results are shown in Table 1. They concluded that $6 \mathrm{wt} \%$ of potassium $(\mathrm{K})$ is the best promoter of the $50 \% \mathrm{Fe}-50 \% \mathrm{Mn}$ based FTS catalyst to produce the $\mathrm{C}_{2}-\mathrm{C}_{4}$ olefins [17]. Besides, $\mathrm{Ni}$ is used as the 
promoter in order to increase $\mathrm{CO}$ conversion and methane selectivity $[43,44]$. A poor promoter can also lead to light gas selectivity due to excessive hydrogenation. Sometimes, concerning long term use, it may require regeneration because certain metals (e.g., $\mathrm{Au}$ ) can be separated from the active materials during oxidation-reduction cycles [28].

Table 1. Effect of different promoters on the catalytic performance of Fe-Mn catalyst [17].

\begin{tabular}{ccccccc}
\hline \multirow{2}{*}{ Promoter (2 wt\%) } & CO Conversion (\%) & \multicolumn{5}{c}{ Product Selectivity (\%) } \\
\cline { 3 - 7 } & & $\mathbf{C H}_{\mathbf{4}}$ & $\mathbf{C}_{\mathbf{2}}-\mathbf{C}_{\mathbf{4}}$ & $\mathbf{C}_{\mathbf{5}}-\mathbf{C}_{\mathbf{9}}$ & $\mathbf{C}_{\mathbf{1 0}}+$ & $\mathbf{C O}_{\mathbf{2}}$ \\
\hline $\mathrm{Zn}$ & 34.1 & 22.3 & 46.0 & 14.4 & 6.5 & 10.8 \\
$\mathrm{Rb}$ & 28.7 & 24.5 & 32.8 & 21.1 & 9.4 & 12.2 \\
$\mathrm{Cs}$ & 38.4 & 21.1 & 41.7 & 15.4 & 11.7 & 10.1 \\
$\mathrm{~K}$ & 43.8 & 16.4 & 51.7 & 14.4 & 9.2 & 8.3 \\
$\mathrm{Ce}$ & 32.5 & 25.1 & 37.2 & 18.1 & 8.2 & 11.4 \\
& \multicolumn{2}{l}{ Reaction conditions: $\mathrm{H}_{2} / \mathrm{CO}=2, \mathrm{GHSV}=1200 \mathrm{~h}^{-1}, \mathrm{P}=1 \mathrm{~atm}$ and $250{ }^{\circ} \mathrm{C}$} \\
\hline
\end{tabular}

\subsection{Support Materials}

For the improvement of the FTS reaction performance, support materials are a crucial factor that can improve the physical properties such as mechanical strength, active component dispersion, heat and mass transfer, and stability of the catalysts. $\mathrm{Al}_{2} \mathrm{O}_{3}, \mathrm{SiO}_{2}, \mathrm{TiO}_{2}$, and $\mathrm{ZrO}_{2}$ are generally used as supports due to their high surface area and strong mechanical strength [45-62]. The selection of support results in active material dispersion. Well-defined surface area and pore structure strongly enhance dispersion and reducibility of the active materials, which can improve the long term stability of the catalyst as well as the catalytic activity toward reactions such as CO conversion. [27,63-66]. However, in addition to the aforementioned physical properties, chemical properties such as chemical interaction between active and support materials should also be considered because reducibility, metal particle size, and shape are affected by the strong metal surface interaction (SMSI) [67-71]. The strong metal support interaction affects the active metal shape and the size during $\mathrm{H}_{2}$ reduction on top of the support. The nature of active metal on the surface of the support is affected by the supporter material. The SMSI can affect the surface metal reducibility by the oxygen sharing phenomenon from the support materials. It can migrate the nature on top of the supported metal nanoparticles, inhibiting their $\mathrm{H}_{2}$ and $\mathrm{CO}$ chemisorption capacity. Thus, the chemical strength between the active metals and their supports is important.

\section{Recent Approaches}

Numerous works have reported increases in the selectivity toward the desired products. In literature, there are different preparations of catalysts for light hydrocarbon or middle distillate production precipitation, co-precipitation, co-precipitation in slurry, impregnation, hydrothermal synthesis, etc. In this section, we describe some recent approaches.

\subsection{Hybrid Catalysts with Cracking Catalysts}

For the purpose of direct liquid hydrocarbon production, the simplest approach is well known to involve a combination of FTS and cracking catalysts. However, technically, four types of catalyst can be categorized, as shown in Figure 7 [27]. First, from the review literature, the simplest hybrid catalysts are the two-bed catalysts with a simple layered structure composed of FTS and cracking catalysts. The second type is a one-bed catalyst that consists of a mixed catalyst in a bed or in a catalyst template. The third type is a catalyst coated or layered onto an FTS catalyst. The fourth type is an active phase supported on a zeolite. Some authors have suggested that the improved performance of one-bed over two-bed systems results in increased selectivity toward gasoline-range hydrocarbons on Co-based catalysts. For Fe-based catalysts, supported or coated systems have been shown to be more selective than one-bed systems toward the $C_{5}-C_{11}$ fraction [72,73]. According to Sartipi et al. [27], 
the combination of zeolites with an active FTS phase increases the product selectivity toward liquid hydrocarbons. This approach offers great potential for intensified and direct production of synthetic fuels from syngas. Among different zeolite topologies, the most promising results have been obtained with H-ZSM-5 (H formed Zeolite Socony Mobil-5; aluminosilicate zeolite).
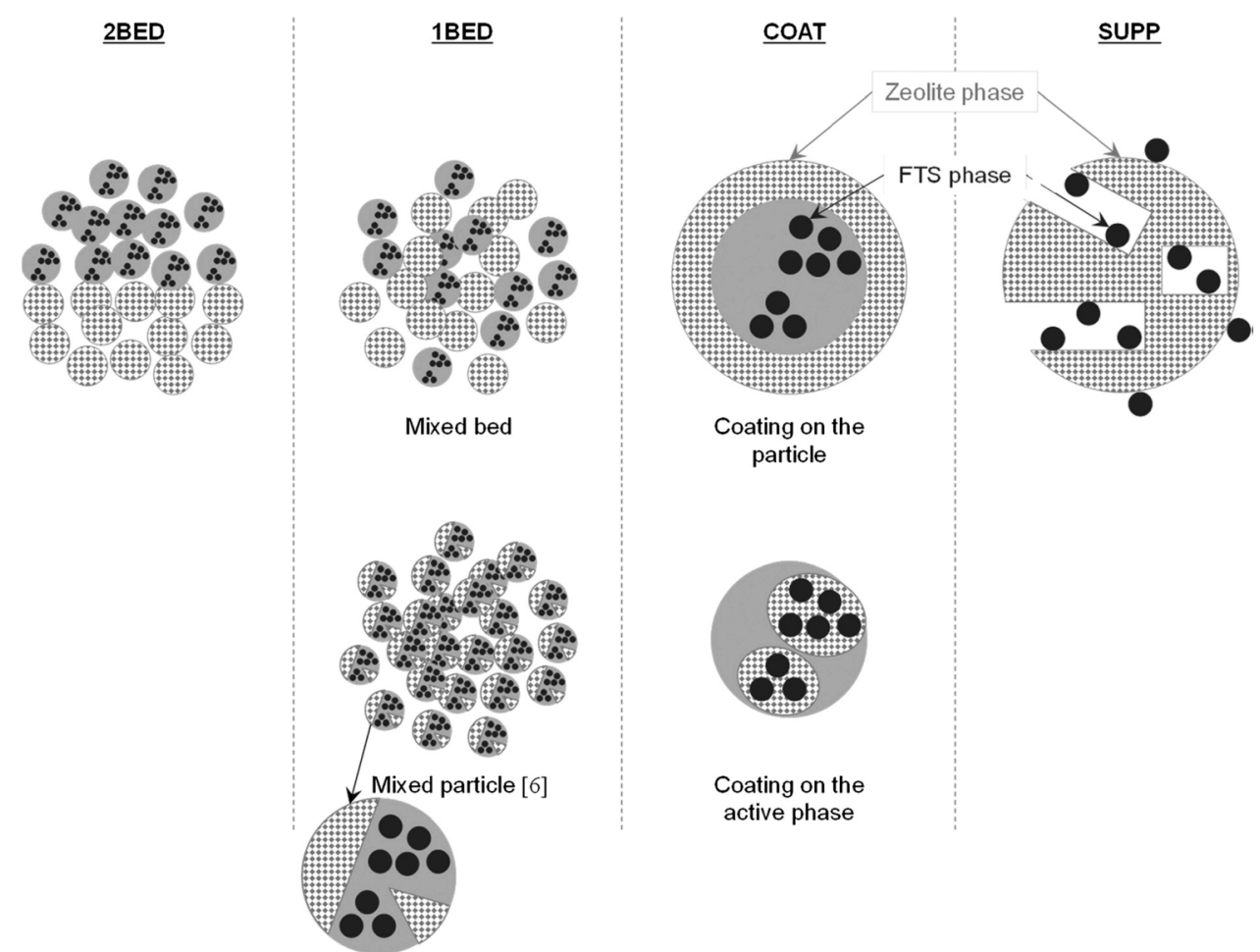

Figure 7. Schematic of different configurations that zeolite and FTS phases can assume with respect to one another in bifunctional systems. Reprinted with permission from [27]. Copyright (2014) RSC Cambridge, England.

\subsection{Encapsuled Core-Shell Catalysts}

As previously mentioned, coated catalysts are advanced catalysts sometimes called core-shell or capsule catalysts. Yang et al. [74-76] reported on the performance of $\mathrm{H}-\mathrm{ZSM}-5 / \mathrm{Co} / \mathrm{SiO}_{2}$ capsule catalysts with different sizes for the direct synthesis of iso-paraffins under FTS reaction conditions, as shown in Figure 8 [74]. Calderone et al. [77] reported improved results with respect to catalyst deactivation of Fe-based catalysts when they were used to coat a Co core, resulting in a Co-Fe core-shell catalyst. The difference in stability of the two catalysts with time on stream is shown in Figure 9. The Fe-based catalyst shows a higher starting activity but loses $50 \%$ of its activity after just $10 \mathrm{~h}$ and becomes almost inactive after $90 \mathrm{~h}$. Conversely, the core-shell catalyst, although less active, retains its activity throughout the duration of the test. The schematic of the encapsulated core-shell FTS catalysts reported by Jin et al. is shown in Figure 10 [78]. In addition, TEM images of encapsulated core-shell catalysts used in an FTS reaction were reported after 2011 (Figure 11) $[79,80]$. The results obtained in these studies indicate superior selectivity toward the desired products [74-84]. For example, a Co@Ru core-shell structure led to a substantial increase in $\mathrm{CO}$ conversion and $\mathrm{C}_{5}+$ selectivity (Table 2) [79]. 
Table 2. FTS product distributions achieved with various synthesized catalysts [85].

\begin{tabular}{ccccc}
\hline \multirow{2}{*}{ Catalysts } & $\begin{array}{c}\text { Reaction } \\
\text { Temperature }\left({ }^{\circ} \mathbf{C}\right)\end{array}$ & \multicolumn{3}{c}{ Hydrocarnon Selectivity (\%) } \\
\cline { 3 - 5 } & 220 & $\mathbf{C H}_{\mathbf{4}}$ & $\mathbf{C}_{\mathbf{2}}-\mathrm{C}_{\mathbf{4}}$ & $\mathrm{C}_{\mathbf{5}}+$ \\
\hline \multirow{2}{*}{$5 \mathrm{Co} / \gamma-\mathrm{Al}_{2} \mathrm{O}_{3}$} & 230 & 24.06 & 51.59 & 24.33 \\
& 220 & 13.43 & 30.12 & 25.39 \\
\hline \multirow{2}{*}{$5 \mathrm{Co}-0.55 \mathrm{Ru} / \gamma-\mathrm{Al}_{2} \mathrm{O}_{3}$} & 230 & 13.12 & 32.24 & 53.55 \\
& 220 & 13.31 & 27.93 & 58.75 \\
\hline \multirow{2}{*}{$5 \mathrm{Co}-1.25 \mathrm{Ru} / \gamma-\mathrm{Al}_{2} \mathrm{O}_{3}$} & 230 & 12.49 & 26.21 & 61.28 \\
\hline \multirow{2}{*}{$5 \mathrm{Co}-2.14 \mathrm{Ru} / \gamma-\mathrm{Al}_{2} \mathrm{O}_{3}$} & 220 & 11.48 & 22.43 & 66.07 \\
& 230 & 11.20 & 21.90 & 66.88 \\
\hline \multirow{2}{*}{$5 \mathrm{Co}-3.33 \mathrm{Ru} / \gamma-\mathrm{Al}_{2} \mathrm{O}_{3}$} & 220 & 17.02 & 15.08 & 67.94 \\
& 230 & 16.86 & 17.94 & 68.27 \\
\hline \multirow{2}{*}{$5 \mathrm{Co}-5 \mathrm{Ru} / \gamma-\mathrm{Al}_{2} \mathrm{O}_{3}$} & 220 & 18.37 & 13.75 & 67.86 \\
& 230 & 17.86 & 13.36 & 68.76 \\
\hline
\end{tabular}

Reaction conditions: $2 \mathrm{MPa}, \mathrm{CO} / \mathrm{H}_{2}=2, \mathrm{GHSV}=900 \mathrm{~h}^{-1}$; $\mathrm{Co}$ and $\mathrm{Ru}$ are weight percent $(\mathrm{wt} \%)$.

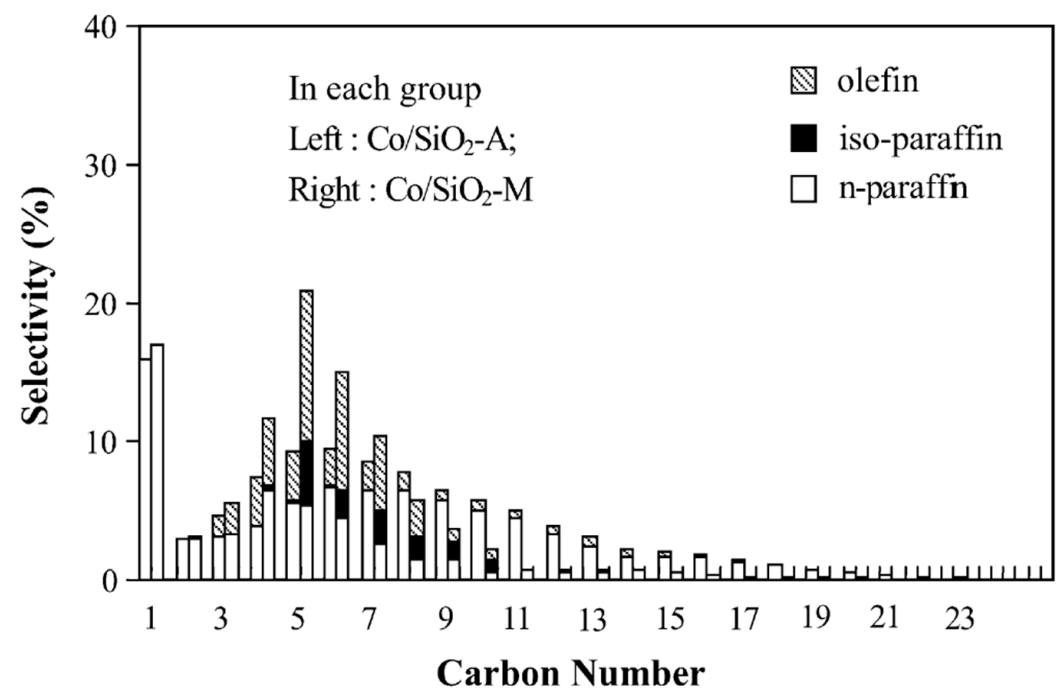

Figure 8. Product distribution of FTS reaction on the zeolite capsule catalysts. Reprinted with permission from [74]. Copyright (2007) Elsevier Science BV, Amsterdam, The Netherlands.

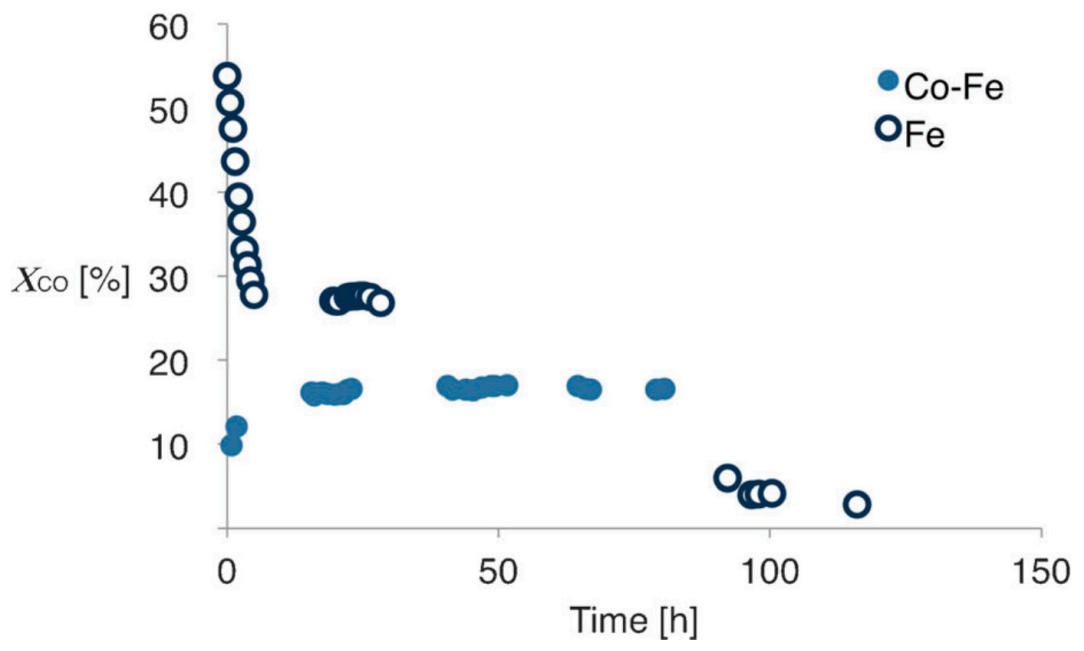

Figure 9. Catalytic activity expressed in terms of CO conversion. Reprinted with permission from [77]. Copyright (2013) Wiley-VCH Verlag GMBH, Weinheim, Germany. 


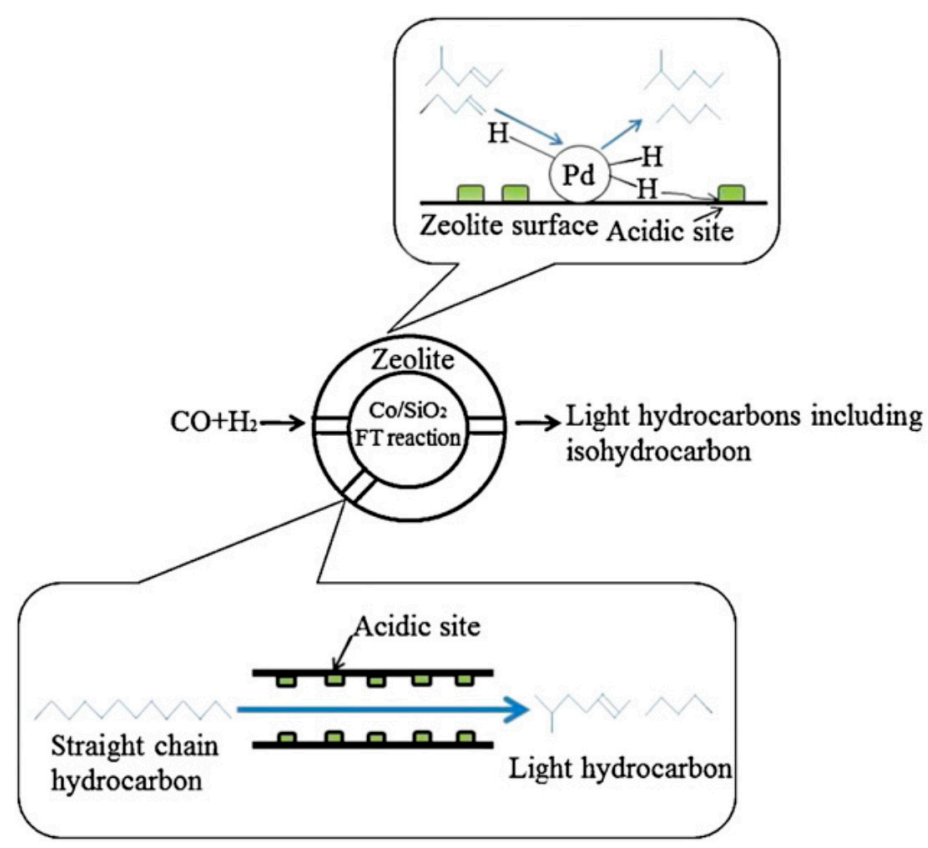

Figure 10. Schematic of the actions of the $\mathrm{Co} / \mathrm{SiO}_{2}-\mathrm{Z}-\mathrm{Sp}-\mathrm{Pd}$ catalyst in the FTS reaction. Reprinted with permission from [78]. Copyright (2013) Elsevier Science BV, Amsterdam, Netherlands.
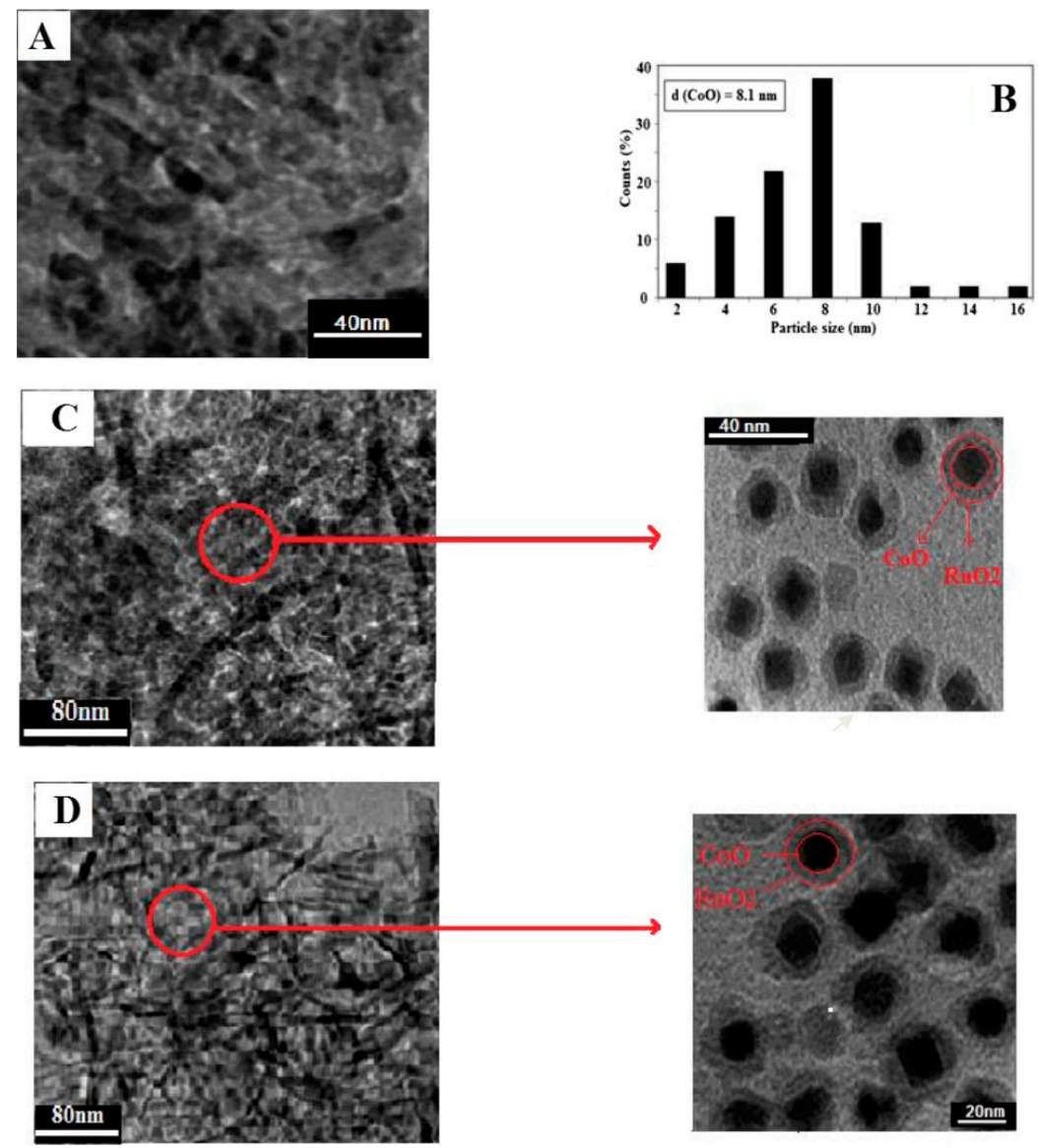

Figure 11. High-resolution TEM (HRTEM) image of $5 \mathrm{Co} / \gamma-\mathrm{Al}_{2} \mathrm{O}_{3}(\mathbf{A})$, cobalt oxide particle size histogram of $5 \mathrm{Co} / \gamma-\mathrm{Al}_{2} \mathrm{O}_{3}$ (B), HRTEM image of $5 \mathrm{Co}-0.55 \mathrm{Ru} / \gamma-\mathrm{Al}_{2} \mathrm{O}_{3}$ (C), HRTEM image of $5 \mathrm{Co}-2.14 \mathrm{Ru} / \gamma-\mathrm{Al}_{2} \mathrm{O}_{3}$ (D). Reprinted with permission from [79]. Copyright (2014) Pergamon-Elsevier Science LTD., Oxford, England. 


\subsection{Catalysts with Well Organized Size and Shape Active Material}

In the early 1990s, Ponec reported activity differences related to the CO adsorption position on the surface of catalysts (e.g., promoter or active metal); however, the suggestions were based on simulations related to the structure and the composition of active sites using broad collected data [11]. Although the shape of a catalyst's surface is difficult to define, researchers can now directly observe surface shape and manufacture materials with controlled specific shapes and sizes because imaging technologies such as scanning electron microscopy (SEM), scanning transmission electron microscopy (STEM), and high-resolution transmission electron microscopy (HRTEM) have become more advanced and more accessible.

The literature contains only a few reports of sophisticated controlled nano-sizing and shaping technologies in the field of fuel cells and water electrolysis for hydrogen generation. Calderone et al., for example, reported a well-organized cobalt oxide particle with a particle size of $7 \mathrm{~nm}$ [77]. Christopher et al. surmised that hierarchical porous materials can benefit certain catalytic applications (e.g., C-C bond-forming reactions) [85]. $\mathrm{C}_{5}+$ selectivity is changed with various manufacturing methods of active materials (shown in Figure 12) [86]. In addition, Liu et al. and Chen et al. summarized the particle size and the crystal phase effect of $\mathrm{Fe}, \mathrm{Co}$, and Ru-based FTS catalysts [87,88]. From their review report, for the Fe-based catalysts, the smaller iron carbide particles display higher turnover frequency (TOF) for $\mathrm{CO}$ conversion, but with the high $\mathrm{CO}$ conversion, the particle size is less than about $6 \mathrm{~nm}$. However, in the case of Ru- and Co-based catalysts, the crystal phase is more important (Co-based; hexagonal closed packed (HCP), Ru-based; face centered cubic (FCC)), because the different morphologies by the crystal phases affect the electronic stats and result in substantial activity and selectivity $[87,88]$.

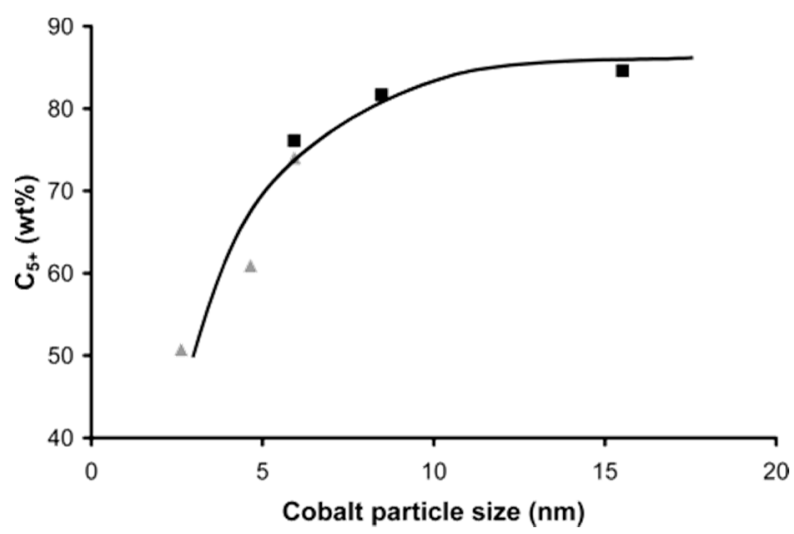

Figure 12. The influence of cobalt particle size on the $\mathrm{C}_{5}+$ selectivity. Reprinted with permission from [86]. Copyright (2009) American Chemical Society (ACS), Washington, DC, America.

\subsection{Catalysts on Shape- and Size-Controlling Supports}

In some cases, FTS catalysts with well-organized supports have shown better selectivity toward the desired product. One example is the MCM-41-supported Co-Ru catalyst reported by Bahome et al. (denoted MCM-41 means Mobil Composition of Matter No. 41 which has the mesoporous hierarchical structure) [53]. The MCM-41-supported catalysts have Brunauer-Emmett-Teller (BET) surface areas of $200-300 \mathrm{~m}^{2} / \mathrm{g}$, a maximum pore size distribution of $7 \mathrm{~nm}$, and well-organized XRD patterns with (100) index. However, the results of $\mathrm{N}_{2}$ adsorption, $\mathrm{H}_{2}$ chemisorption, and energy-dispersive $\mathrm{X}$-ray spectroscopy (EDX) experiments suggest that some of the pores were blocked when a large amount of Co was impregnated into the small-pore MCM-41, resulting in a non-uniform distribution of Co. Nonetheless, higher reaction rates were observed, even with the higher Co-content catalysts because of the good dispersion of the active material (Co). In addition, even though the reaction differs from the FTS reaction, Parlett et al. reported that a Pd/mesoporous $\mathrm{SiO}_{2}$ (KIT-6, SBA-16, SBA-15) catalyst enhances the aerobic oxidation of alcohols (denoted KIT-6 means highly ordered cubic Ia3d silica 
templated by P123 block-copolymer surfactant and SBA means Santa Barbara Amorphous which is well-ordered mesoporous silica templated by triblock copolymer) [89]. These results indicate that well-organized support materials not only provide a large surface area for the dispersion of active materials but also provide the best selectivity of the desired product via control of the mass transfer of reactants and products and that such enhancements are not limited to FTS reactions.

With advances in nanoscale manufacturing technologies, carbon nanotubes (CNTs) have been used to control shape and size of the active materials of FTS catalysts. Bahome et al. reported an Fe-based CNT-supported catalyst for the FTS reaction. They used various methods to load Fe into the CNTs (average diameter of $15 \mathrm{~nm}$ ) [53]. Xiong et al. discussed shaped carbons that led to improved catalytic conversion from syngas in their review paper [90]. Their summarized results of the research theme of carbon black- and activated carbon-supported catalysts for the FTS reaction are presented in Table 3 [90]. The summary includes results for catalysts supported on carbon nanofibers (CNFs) and CNTs, ordered mesoporous carbon (OMC), graphene, and graphite. In the case of CNFs and CNTs, the FTS reactions are affected by pretreatment, pore size, and structure of the carbon materials as well as by the particle size of the active materials. For example, when CNTs were pretreated with HNO3, the BET surface area of the CNTs increased because of the formation of defects. The larger surface area led to greater reducibility, which in turn led to greater CO conversion [91].

Table 3. Carbon properties, reaction conditions, and research theme of carbon black- and activated carbon-supported catalysts used in Fischer-Tropsch synthesis [42].

\begin{tabular}{|c|c|c|c|c|c|}
\hline \multirow{2}{*}{ Catalysts } & \multirow{2}{*}{$\begin{array}{l}\text { Support Type } \\
\text { and Property }\end{array}$} & \multicolumn{2}{|c|}{ FTS Conditions } & \multirow{2}{*}{$\begin{array}{l}\text { Reaction } \\
\text { Parameter }\end{array}$} & \multirow{2}{*}{ Performance } \\
\hline & & Reduction & Reaction & & \\
\hline $\mathrm{Fe} / \mathrm{CB}$ & Columbia, T-10157 & $400^{\circ} \mathrm{C}$ & $\begin{array}{c}0.1 \mathrm{MPa}, 275^{\circ} \mathrm{C}, \mathrm{H}_{2}: \\
\mathrm{CO}=1-9\end{array}$ & porosity, stability & $\begin{aligned} X & =\text { N.A., } \\
\mathrm{S}_{5+} & =2-10 \%\end{aligned}$ \\
\hline $\mathrm{Fe} / \mathrm{CB}$ & $\mathrm{SA}=763 \mathrm{~m}^{2} / \mathrm{g}$ & $300^{\circ} \mathrm{C}, 0.5 \mathrm{MPa}$ & $\begin{array}{c}260-280^{\circ} \mathrm{C}, 20 \mathrm{MPa}, \\
\mathrm{H}_{2} / \mathrm{CO}=1\end{array}$ & $\begin{array}{l}\text { support effect, } \\
\text { ozone treatment }\end{array}$ & $\begin{array}{r}X=40-80 \%, \\
S_{5+}=60-80 \%\end{array}$ \\
\hline $\mathrm{Fe} / \mathrm{CB}$ & $\begin{array}{c}\text { Vulcan } 3 \\
\left(\mathrm{SA}=56 \mathrm{~m}^{2} / \mathrm{g}\right)\end{array}$ & $400^{\circ} \mathrm{C}$ & $\begin{array}{c}275^{\circ} \mathrm{C}, 101 \mathrm{kPa} \\
\mathrm{H}_{2} / \mathrm{CO}=3\end{array}$ & dispersion effect & $\begin{array}{l}\mathrm{X}=2.8-3.9 \%, \\
\mathrm{~S}_{5+}=5-12 \%\end{array}$ \\
\hline $\mathrm{Ru} / \mathrm{CB}$ & V3G $\left(62 \mathrm{~m}^{2} / \mathrm{g}\right)$ & $400^{\circ} \mathrm{C}$ & $\begin{array}{c}190-250^{\circ} \mathrm{C} 101 \mathrm{kPa} \\
\mathrm{H}_{2} / \mathrm{CO}=3\end{array}$ & $\begin{array}{l}\text { selectivity, } \\
\text { interaction }\end{array}$ & $\begin{array}{c}\mathrm{X}=1.5-4.5 \%, \\
\mathrm{~S}_{5+}<1 \%\end{array}$ \\
\hline $\mathrm{Fe} / \mathrm{AC}$ & from olive pits & $400{ }^{\circ} \mathrm{C}$ & $\begin{array}{c}0.1 \mathrm{MPa}, 275^{\circ} \mathrm{C} \\
\mathrm{H}_{2} / \mathrm{CO}=3\end{array}$ & porosity, stability & $\begin{array}{c}\mathrm{X}=2-27 \% \\
\mathrm{~S}_{5+}=2-10 \%\end{array}$ \\
\hline $\begin{array}{l}\mathrm{Fe}-\mathrm{K} / \mathrm{AC} \\
\mathrm{Fe}-\mathrm{Cu} / \mathrm{AC}\end{array}$ & Sigma-Aldrich & $400^{\circ} \mathrm{C}, 0.5 \mathrm{MPa}$ & $\begin{array}{c}280^{\circ} \mathrm{C}, 300 \mathrm{psig}, \\
\mathrm{H}_{2} / \mathrm{CO}=0.9\end{array}$ & $\begin{array}{l}\text { Cu promoter } \\
\text { effect }\end{array}$ & $\begin{array}{l}X=28-85 \%, \\
S_{5+}=50-61 \%\end{array}$ \\
\hline Fe-Mo-Cu-K/AC & $\begin{array}{l}\text { from peat, generic, } \\
\text { wood, pecan, } \\
\text { walnut }\end{array}$ & $400^{\circ} \mathrm{C}, 0.5 \mathrm{MPa}$ & $\begin{array}{c}290^{\circ} \mathrm{C}, 300 \mathrm{psig} \\
\mathrm{H}_{2} / \mathrm{CO}=0.9\end{array}$ & $\begin{array}{l}\text { K promoter, } \mathrm{AC} \\
\text { nature effects }\end{array}$ & $\begin{array}{r}X=29-97 \%, \\
S_{5+}=16-62 \%\end{array}$ \\
\hline $\mathrm{Fe} / \mathrm{AC}$ & $\mathrm{SA}=1170 \mathrm{~m}^{2} / \mathrm{g}$ & $300^{\circ} \mathrm{C}, 0.5 \mathrm{MPa}$ & $\begin{array}{c}260-280^{\circ} \mathrm{C}, 2.0 \mathrm{MPa}, \\
\mathrm{H}_{2} / \mathrm{CO}=1\end{array}$ & $\begin{array}{l}\text { support effect, } \\
\text { ozone treatment }\end{array}$ & $\begin{array}{l}\mathrm{X}=40-80 \%, \\
\mathrm{~S}_{5+}=60-80 \%\end{array}$ \\
\hline $\mathrm{Co} / \mathrm{AC}$ & N.A. & $400^{\circ} \mathrm{C}$ & $\begin{array}{c}220-250^{\circ} \mathrm{C}, 2-4 \mathrm{MPa} \\
\mathrm{H}_{2} / \mathrm{CO}=1.0-2.5\end{array}$ & $\begin{array}{l}\text { Product, } \\
\text { distribution, } \\
\text { kinetics }\end{array}$ & $\begin{array}{l}X=10-54 \%, \\
S_{5+}=\text { N.A. }\end{array}$ \\
\hline $\begin{array}{c}\mathrm{Zr}-\mathrm{Co} / \mathrm{AC} \\
\mathrm{La}-\mathrm{Zr}-\mathrm{Co} / \mathrm{AC}\end{array}$ & $\begin{array}{l}\mathrm{SA}=1068.7 \mathrm{~m}^{2} / \mathrm{g} \\
\mathrm{PV}=0.65 \mathrm{~cm}^{3} / \mathrm{g}\end{array}$ & $400^{\circ} \mathrm{C}$ & $\begin{array}{c}250^{\circ} \mathrm{C}, 2.5 \mathrm{MPa}, \\
\mathrm{H}_{2} / \mathrm{CO}=2\end{array}$ & $\begin{array}{l}\text { Lanthanum, } \\
\text { promoter }\end{array}$ & $\begin{array}{l}\mathrm{X}=49-93 \%, \\
\mathrm{~S}_{5+}=63-75 \%\end{array}$ \\
\hline ZSM-5-Fe/AC & $\begin{array}{l}\text { Norit SX Ultra } \\
\text { (Sigma-Aldrich) }\end{array}$ & $1 \mathrm{~atm}, 400{ }^{\circ} \mathrm{C}$ & $\begin{array}{c}280-320^{\circ} \mathrm{C}, 300 \mathrm{psig}, \\
\mathrm{H}_{2} / \mathrm{CO}=1\end{array}$ & zeolite promoter & $\begin{array}{c}X=70-90 \% \\
S_{5+}=\text { N.A }\end{array}$ \\
\hline $\mathrm{Fe}-\mathrm{Cu}-\mathrm{K} / \mathrm{AC}$ & Sigma-Aldrich & $0.5 \mathrm{MPa}, 400^{\circ} \mathrm{C}$ & $\begin{array}{c}310-320^{\circ} \mathrm{C}, 2.2 \mathrm{MPa}, \\
\mathrm{H}_{2} / \mathrm{CO}=0.9\end{array}$ & $\begin{array}{l}\text { Mo promoter, } \\
\text { reducibility }\end{array}$ & $\begin{aligned} X & =\text { N.A., } \\
S_{5+} & =39-52 \%\end{aligned}$ \\
\hline
\end{tabular}

\subsection{Other Approaches}

Ekbashir and Buker [92] reviewed advanced FTS reactions in a supercritical fluid extractor. They asserted that the supercritical extractor helps overcome transport limitations, integrate reaction processes, and enhance in situ extraction of low-volatility products (e.g., heavy hydrocarbons) from 
porous catalysts. Fan and Fujimoto [93] investigated the effect of supercritical extraction on the olefin contents of hydrocarbon products using a $\mathrm{Ru} / \mathrm{Al}_{2} \mathrm{O}_{3}$ catalyst. Their results showed that the supercritical-phase reaction enhanced olefin yield with a wide range of product carbon numbers because the hydrogenation rate increased relative to the diffusion rate with increasing carbon number of the products.

Computation studies are recently being advised in the field of kinetics and engineering simulations for the design of more efficient catalysts and novel reactor technologies (e.g., microchannel reactor and monolith reactor). For the FTS reaction, Mendez et al. are trying to generalize the modeling scheme of the fixed-bed reactor [94]. In addition, computational studies by Jacobs et al. [28] indicate that certain promoters can inhibit polymeric $\mathrm{C}$ formation by hindering $\mathrm{C}-\mathrm{C}$ coupling.

\section{A State-of-Arts in South Korea}

\subsection{Zeolite Supported Catalyst}

\subsubsection{Dual-Bed Catalysts}

Park et al. reported on FTS in a dual-bed reactor including an FTS catalyst and a cracking catalyst for the production of $\mathrm{C}_{2}-\mathrm{C}_{4}$ olefins directly from synthesis gas. The $\mathrm{Fe}-\mathrm{Cu}-\mathrm{Al}$-based FTS catalyst and the ZSM-5 cracking catalyst were used in a consecutive dual-bed reactor system. The FTS catalyst was Fe-based, such as $\mathrm{Fe}-\mathrm{Cu}-\mathrm{Al}$, and ZSM-5 was used as the cracking catalyst. As a result, the first bed ( $\mathrm{Fe}-\mathrm{Cu}-\mathrm{Al}$ catalyst) produced little methane and large amounts of $\mathrm{C}_{5}+$ hydrocarbons and the second bed (ZSM-5 catalyst) improved the selectivity toward $C_{2}-C_{4}$ hydrocarbons by $52 \%$ [95].

\subsubsection{Supported with ZSM-5 Focused Olefin Production}

In 2008, Kang et al. used characterization methods such as XRD, temperature-programmed reduction (TPR), and $\mathrm{NH}_{3}$-TPD (Temperature-Programed Desorption) to study the effects of support materials such as ZSM-5, mordenite, and beta zeolite on the activities of Fe-based catalysts prepared via the typical wet-impregnation method with $\mathrm{Cu}$ and $\mathrm{K}$ as a promoter [96]. The $\mathrm{Fe}-\mathrm{Cu}-\mathrm{K} / \mathrm{ZSM}-5$ catalyst showed the highest yield of light olefin $(13.8 \%)$ because of the reducibility of $\mathrm{Cu}$ and the molecular sieve and acidic site effects of the ZSM- 5 support under conditions of a $\mathrm{H}_{2} / \mathrm{CO}$ ratio of 2.0, temperature of $300{ }^{\circ} \mathrm{C}$, pressure of $1.0 \mathrm{MPa}$, and GHSV of $2000 \mathrm{~mL} / \mathrm{g}$-cat after a 5 vol. $\% \mathrm{H}_{2}$ reduction process at $450{ }^{\circ} \mathrm{C}$ for $12 \mathrm{~h}$. The light-olefin selectivity $[\mathrm{O} /(\mathrm{O}+\mathrm{P})$; Olefin/(Oleifin + Paraffin)] was inversely proportional to the total amount of acid sites, as shown in Figure 13. Kang et al. also studied the optimal Si/Al ratio of ZSM-5 for the Fe-Cu-K/ZSM-5 FTS catalysts [97].

After the reports by Kang et al. [96], studies of $C_{2}-C_{4}$ production from syngas were expeditiously focused on optimal catalyst design using ZSM-5 as the support in South Korea. Cheon et al. [98] reported the optimal Fe content of the Fe-Cu-K/ZSM- 5 catalysts to maximize the yield of light olefins. They investigated the catalytic performances with various Fe contents $(5,20,30,40 \mathrm{wt} \%)$. They reported that the optimal Fe content of the catalyst was $30 \%$, which resulted in the highest CO conversion of $89.3 \%$ and the light olefin selectivity $[\mathrm{O} /(\mathrm{O}+\mathrm{P})]$ of $75.2 \%$ because of the formation of $\mathrm{Fe}-\mathrm{C}$, as evaluated using CO-TPR analysis (Figure 14). They also used $\mathrm{NH}_{3}$-TPD experiments to determine that the $\mathrm{Fe}$ content affects the amounts of weakly and strongly acidic sites.

Bae et al. [99] compared the productivity of light olefins by varying the ratio of $\mathrm{Cu}(2,4,6 \mathrm{wt} \%)$ as a co-catalyst in the $\mathrm{Fe}-\mathrm{Cu}-\mathrm{K} / \mathrm{ZSM}-5$ catalyst system prepared by the impregnation method. The addition of $\mathrm{Cu}$ improved the reducibility of the catalyst, and, at $2 \mathrm{wt} \% \mathrm{Cu}$, the catalyst exhibited stable activity and high light-olefin yield. However, when the $\mathrm{Cu}$ content exceeded $2 \mathrm{wt} \%$, re-oxidation phenomena from iron carbide to inactive iron species was observed. 


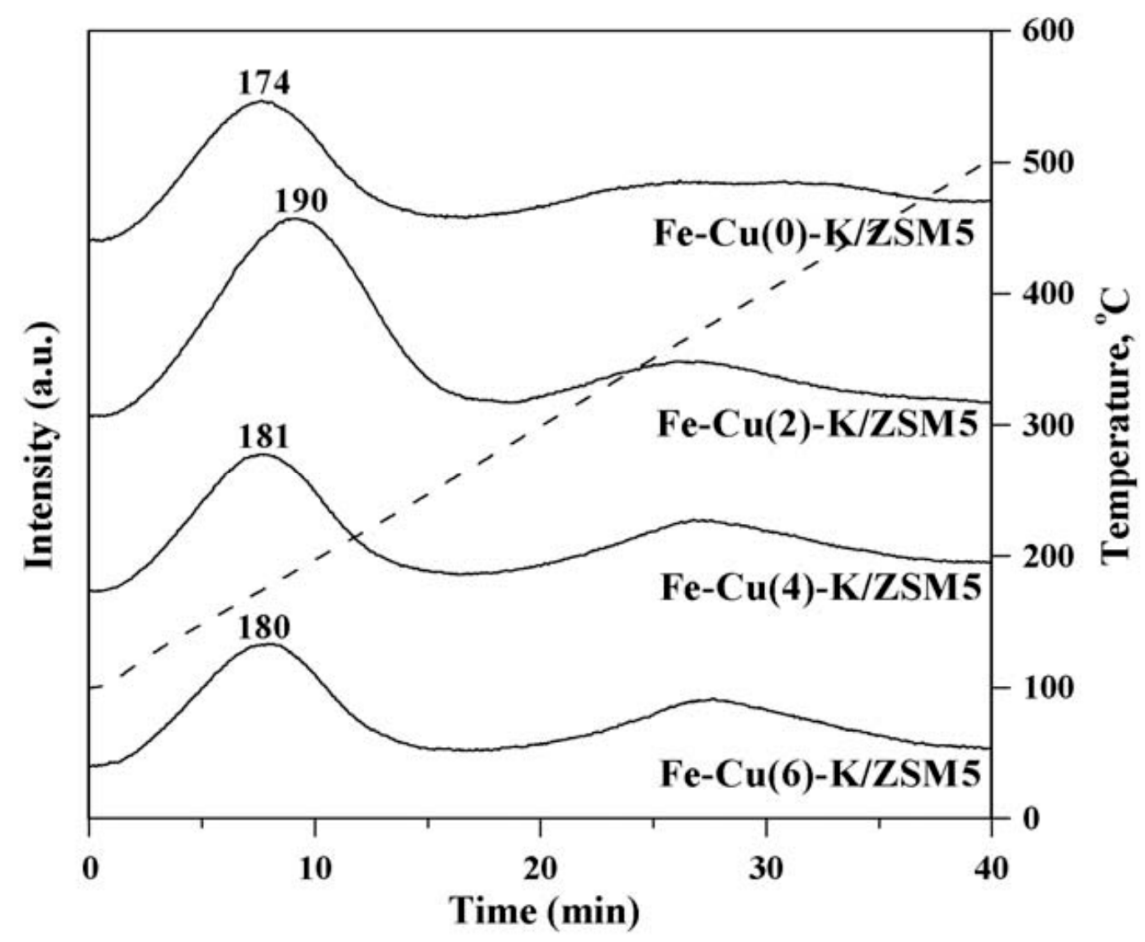

Figure 13. The $\mathrm{NH}_{3}$-TPD profiles over $\mathrm{Fe}-\mathrm{Cu}-\mathrm{K} / \mathrm{ZSM}-5$ catalysts. Reprinted with permission from [99]. Copyright (2009) Elsevier Science Inc., New York, America.

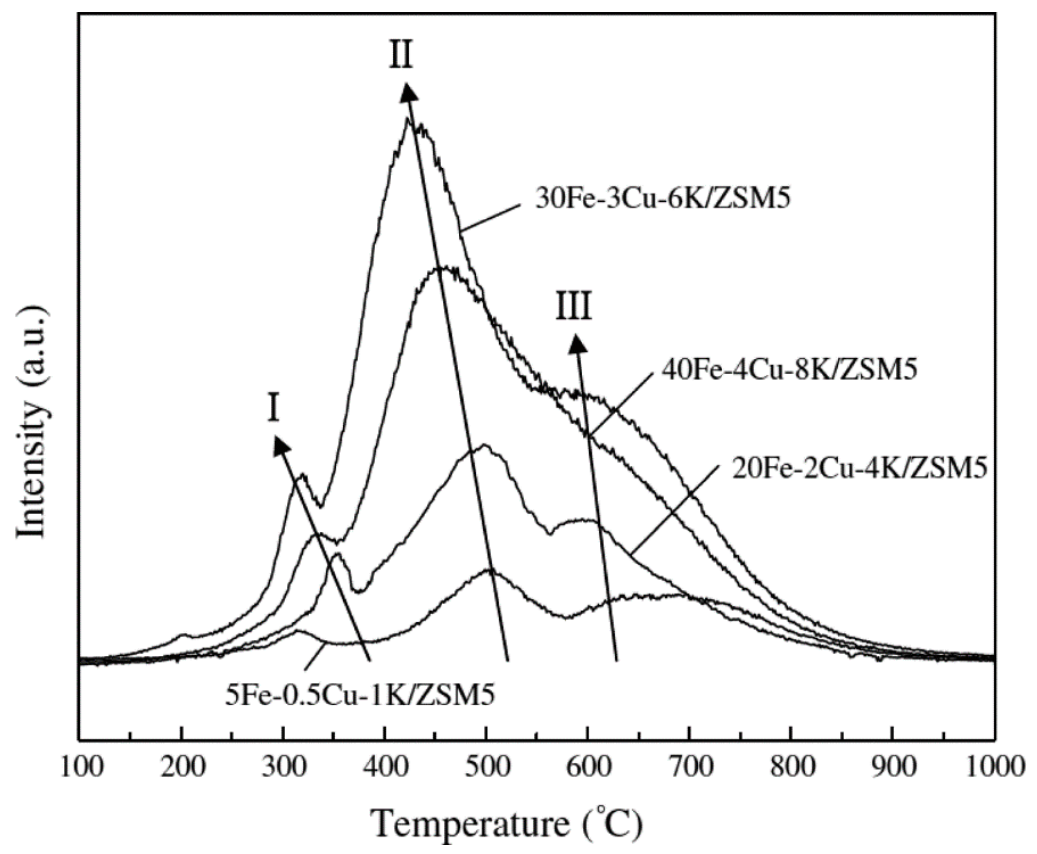

Figure 14. CO- temperature-programmed reduction (TPR) profiles of $\mathrm{Fe}-\mathrm{Cu}-\mathrm{K} / \mathrm{ZSM}-5$ catalysts [98].

\subsubsection{Paraffin Production}

A large amount of recent literature from South Korea has been focused on paraffin light-hydrocarbon production. Unlike studies based on olefin production, these studies were mainly conducted under a $\mathrm{H}_{2} / \mathrm{CO}$ ratio of 3.0 (instead of 2.0). These studies of FTS reactions under high $\mathrm{H}_{2} / \mathrm{CO}$ ratio conditions tend to focus on high-calorific synthetic natural gas production through the simultaneous methanation process during the FTS reaction. 
For these purposes, Kim et al., at the Institute for Advanced Engineering (IAE) in South Korea, registered a patent describing their use of ZSM- 5 as a support and comparison of its catalytic performance [100]. They investigated the performance of various catalysts with different $\mathrm{Ni}$ and Co ratios and different amounts of co-catalyst supported on ZSM- 5 under various conditions. They concluded that the $\mathrm{CO}$ conversion and the $\mathrm{C}_{2}+$ selectivity were improved when the Co content was high or when Ru was used as a co-catalyst. Kim et al. later registered another patent in South Korea in which they compared the FTS processes in a one-stage reactor using a $\mathrm{Co}-\mathrm{Fe}-\mathrm{Ni}$ catalyst supported on $\mathrm{Al}_{2} \mathrm{O}_{3}$ and in a two-stage reactor in which the catalysts were layered, with the $\mathrm{Ni}$ component separated from the other components [101]. In the case of the one-stage reactor using the same $5 \mathrm{CO}-15 \mathrm{Fe}$, when the Ni content was increased, the selectivity of hydrocarbons increased because of a decrease in the conversion ratio from $\mathrm{CO}$ to $\mathrm{CO}_{2}$; nevertheless, the $\mathrm{CH}_{4}$ selectivity was superior to that of $\mathrm{C}_{2}+$. In the case of the two-stage reactor, they obtained enhanced results with a high $\mathrm{CO}$ conversion rate and a high $\mathrm{C}_{2}+$ selectivity of $30.2 \%$.

Kang et al. [102] conducted a study to produce paraffinic light hydrocarbons with $\mathrm{CH}_{4}$ using $\mathrm{Ni}$ and $\mathrm{Fe}$ catalysts on the $\mathrm{Al}_{2} \mathrm{O}_{3}$ support with various $\mathrm{Ni} / \mathrm{Fe}$ ratios. In the case of the Fe content of 0.7 , the $\mathrm{C}_{2}-\mathrm{C}_{5}$ selectivity was the highest, as shown in Figure 15 . They concluded that the higher Fe content was reducing the $\mathrm{CH}_{4}$ and $\mathrm{C}_{2}-\mathrm{C}_{5}$ selectivity because it was enhancing the water-gas shift (WGS) reaction.

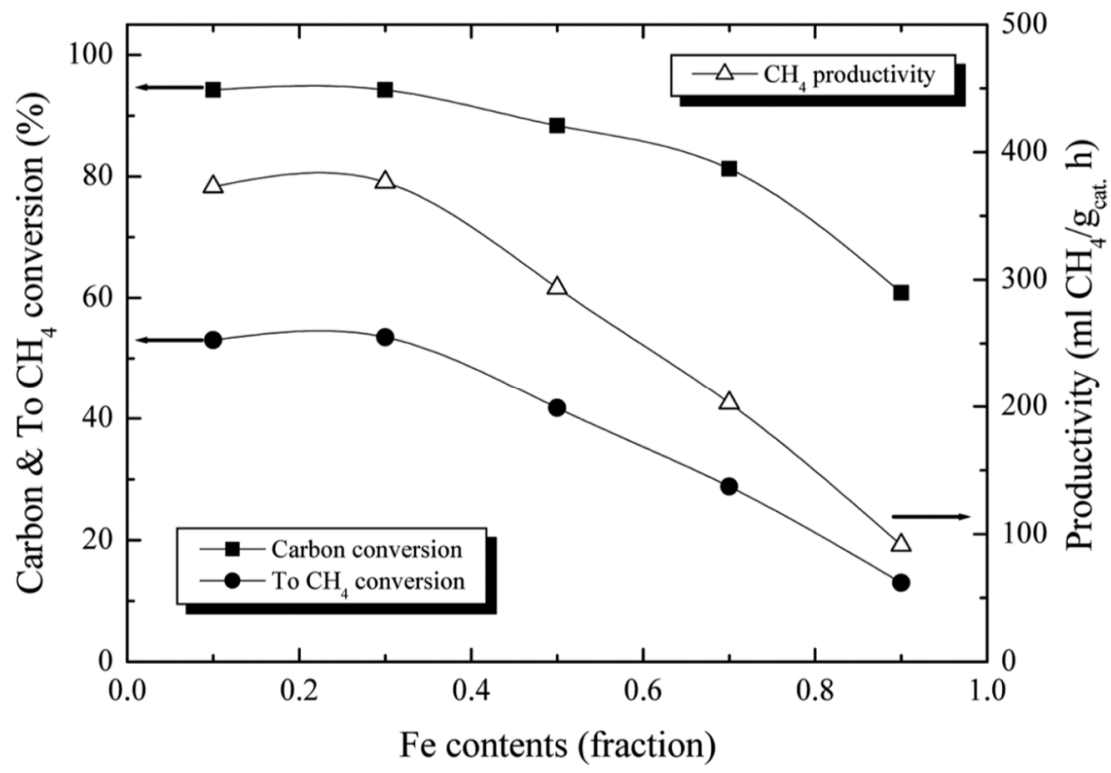

Figure 15. Carbon conversion and $\mathrm{CH}_{4}$ productivity on $\mathrm{Ni}_{1-x} \mathrm{Fe}_{\mathrm{x}} / \mathrm{Al}_{2} \mathrm{O}_{3}$ catalysts according to $\mathrm{Fe}$ contents [102].

Lee et al. used the Fe-based catalysts to produce high-calorific synthetic natural gas [103]. They investigated the effect of the surface properties of the Fe catalysts on their activity toward the production of synthetic natural gas. As the reaction progressed, the adsorption amount of $\mathrm{CO}$ on the surface of the catalyst increased, and the conversion rate of $\mathrm{CO}$ and the selectivity toward $\mathrm{C}_{2}-\mathrm{C}_{4}$ increased.

Jo et al. expeditiously optimized the catalyst design and the operating conditions based on various experimental data, focusing on $\mathrm{C}_{2}-\mathrm{C}_{4}$ selectivity and paraffin ratios $[104,105]$. They investigated the catalytic performances using the various bimetallic ( $\mathrm{Co}$ and $\mathrm{Fe}$ ) catalysts on $\mathrm{Al}_{2} \mathrm{O}_{3}$, where the content of Co was varied; their results are shown in Figure 16. The $5 \mathrm{CO}-15 \mathrm{Fe} / \mathrm{Al}_{2} \mathrm{O}_{3}$ catalyst showed the best performances for the production of light paraffin hydrocarbons due to the iron reducibility for the bimetallic catalysts as shown in Figure 17. They reported the effect of $\mathrm{H}_{2} / \mathrm{CO}$ ratio on the activity of the bimetallic FTS catalyst. The $\mathrm{CO}$ conversion increased remarkably with the temperature at all $\mathrm{H}_{2} / \mathrm{CO}$ ratios. Furthermore, higher $\mathrm{H}_{2} / \mathrm{CO}$ ratios also improved the $\mathrm{CO}$ conversion. With increasing reaction 
temperature, the $\mathrm{CH}_{4}$ yield increases and $\mathrm{C}_{2}+$ yield decreases. The paraffin ratio shows a positive correlation with the $\mathrm{CO}$ conversion according to increasing $\mathrm{H}_{2} / \mathrm{CO}$ ratio, while reaction pressure and temperature have little effect on the paraffin ratio at an $\mathrm{H}_{2} / \mathrm{CO}$ ratio of 3.0. The optimum FTS conditions to produce the highest $\mathrm{C}_{2}-\mathrm{C}_{4}$ paraffin products were determined to be $\mathrm{H}_{2} / \mathrm{CO}=3.0$ and $300{ }^{\circ} \mathrm{C}$ of reaction temperature at 10 bar for the bimetallic $\mathrm{Co}-\mathrm{Fe}$ catalyst supported on the $\gamma$-alumina, as shown in Figure 18. From additional discussion by Jo et al. [105], it was found that CO conversion increases with a decrease in space velocity and with an increase in reaction pressure and temperature, as shown in Figure 19.

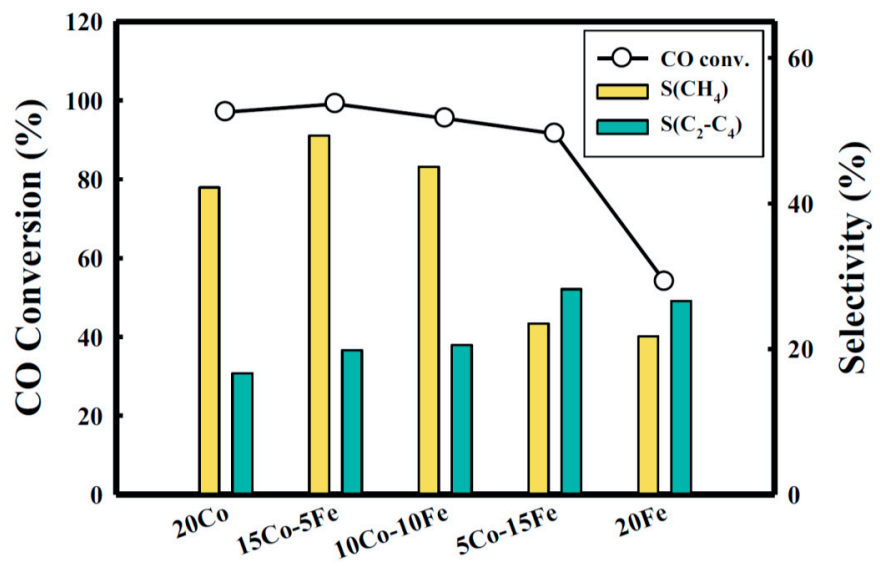

Figure 16. $\mathrm{CO}$ conversion and selectivity of $\mathrm{CH}_{4}$ and $\mathrm{C}_{2}-\mathrm{C}_{4}$ hydrocarbons with various content. Reprinted with permission from [104]. Copyright (2018) Elsevier Science BV, Amsterdam, Netherlands.

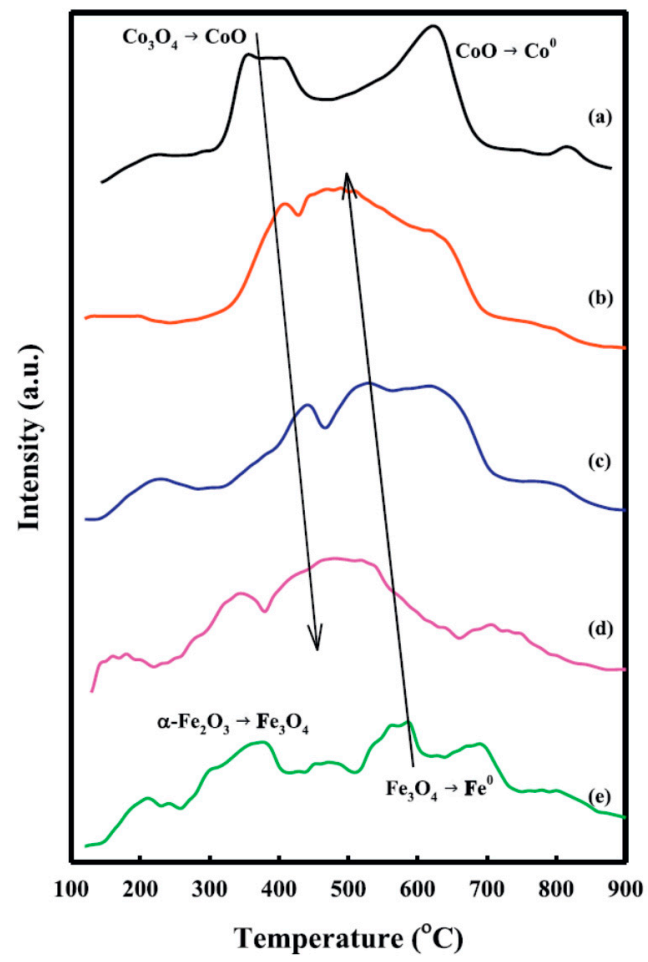

Figure 17. $\mathrm{H}_{2}$-TPR profiles of monometallic and bimetallic catalysts supported on $\gamma$-alumina: (a) $20 \mathrm{Co} / \gamma-\mathrm{Al}_{2} \mathrm{O}_{3}$, (b) $15 \mathrm{Co}-5 \mathrm{Fe} / \gamma-\mathrm{Al}_{2} \mathrm{O}_{3}$, (c) $10 \mathrm{Co}-10 \mathrm{Fe} / \gamma-\mathrm{Al}_{2} \mathrm{O}_{3}$, (d) $5 \mathrm{Co}-15 \mathrm{Fe} / \gamma-\mathrm{Al}_{2} \mathrm{O}_{3}$, and (e) $20 \mathrm{Fe} / \gamma-\mathrm{Al}_{2} \mathrm{O}_{3}$. Reprinted with permission from [104]. Copyright (2018) Elsevier Science BV, Amsterdam, Netherlands. 


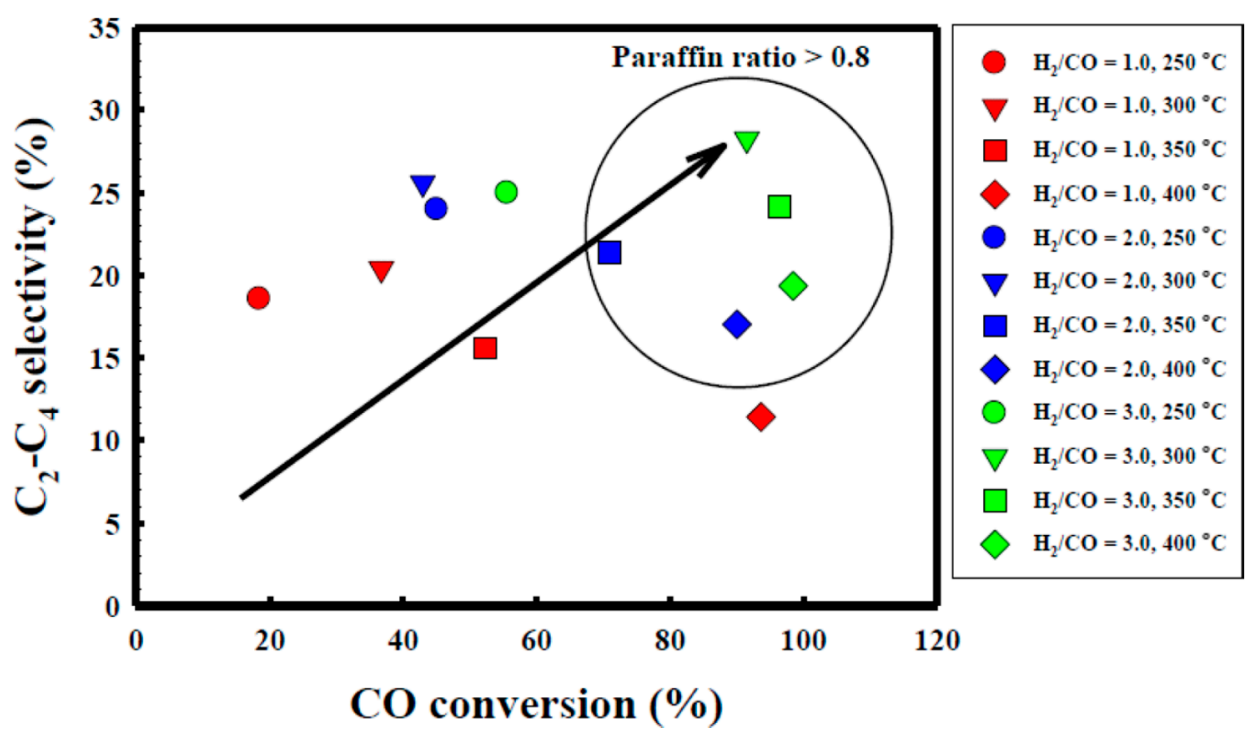

Figure 18. $\mathrm{C}_{2}-\mathrm{C}_{4}$ hydrocarbon selectivity as a function of the $\mathrm{CO}$ conversion. Reprinted with permission from [104]. Copyright (2018) Elsevier Science BV, Amsterdam, Netherlands.

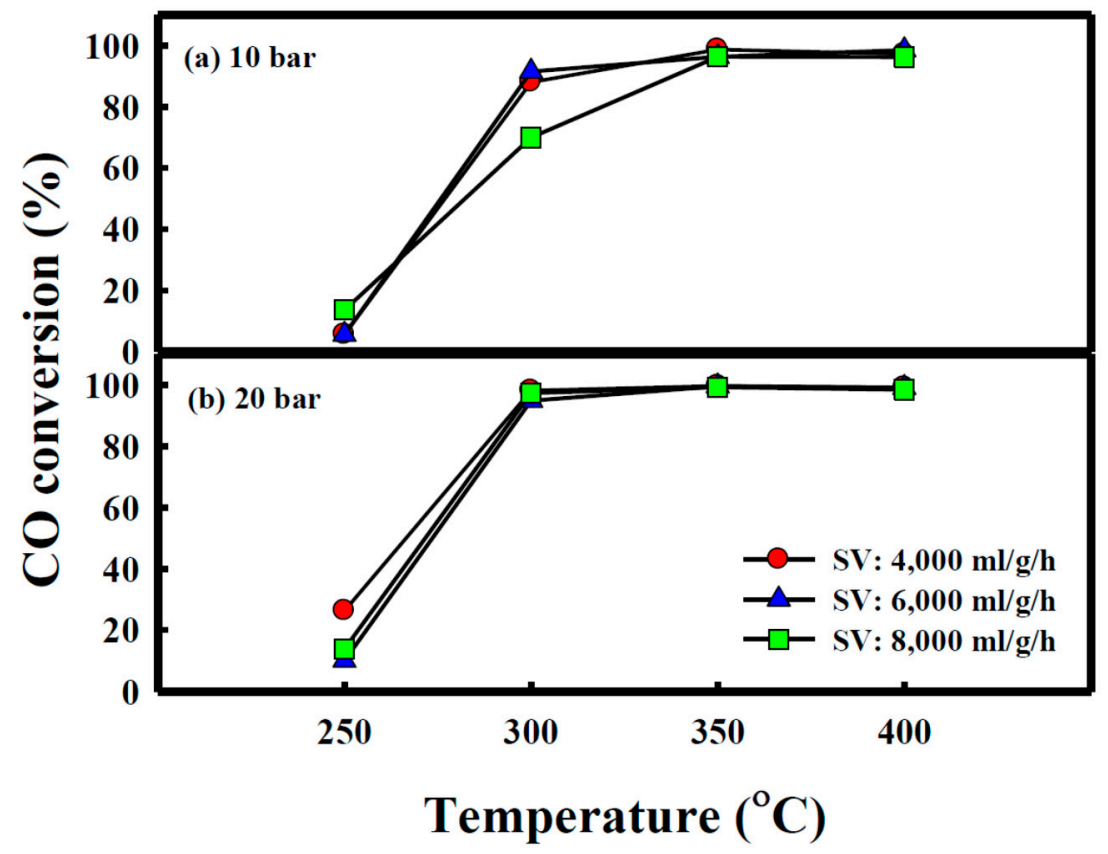

Figure 19. The initial CO conversion under (a) 10 and (b) 20 bar at different space velocities as a function of reaction temperature [105].

\subsubsection{Process Design}

The typical reactor design concepts are not different from the typical heterogeneous catalyst reactor design that is categorized as a fixed-bed, slurry bubble column, circulating and fluidized-bed reactor. In the FTS process, the reactor is chosen appropriately according to the targeted products such as light olefin, gasoline, diesel, or heavy hydrocarbons including wax; the process also requires the selection of an appropriate catalyst preparation method depending on the type of reactor, such as plug flow (fixed-bed or supercritical), fluidized-bed, or slurry bubble column reactor [106,107].

The FTS processes are usually divided by operating temperature ranges of $300-350{ }^{\circ} \mathrm{C}$ (high-temperature FTS; HT-FTS) and $200-240{ }^{\circ} \mathrm{C}$ (low-temperature FTS; LT-FTS). In addition, temperature control is important to prevent catalyst deactivation phenomena such as active material sintering and carbon coke production caused by non-ideal temperature behavior resulting from these 
exothermic reactions. As previously mentioned, typical LT-FTS processes introduced the slurry and the fix-bed reactor to produce linear long-chain hydrocarbons (some paraffin and waxes), and HT-FTS processes introduced the fluidized-bed reactor to produce $C_{2}-C_{15}$ hydrocarbons $[16,108,109]$.

As noted in 3.1.3, Kim et al. compared the one-stage reactor and the two-stage reactor with two layered catalysts [101]. The dual-bed reactor exhibited improved the $\mathrm{C}_{2}-\mathrm{C}_{4}$ selectivity, as shown in Figure 20 [110]. However, Kang et al. [111] reported other research on the performance of a fixed-bed reactor (FBR) and a bubbling fluidized-bed reactor (BFBR) using an Fe-based catalyst-the two types of reactors used in their work. Under similar operating conditions (e.g., temperature and pressure), the $\mathrm{C}_{2}-\mathrm{C}_{4}$ selectivity and the olefin selectivity in the BFBR were higher than those in the FBR with $\mathrm{K} / \mathrm{FeCuAlOx}$ and $\mathrm{K} / \mathrm{FeOx}$ catalysts. They suggested that the $\mathrm{K} / \mathrm{FeCuAlOx}$ and the $\mathrm{K} / \mathrm{FeOx}$ catalysts are candidates for use in BFBRs for the MT-FTS (middle-temperature Fischer-Tropsch, typically conducted at $\sim 300{ }^{\circ} \mathrm{C}$ ) reaction with high $\mathrm{C}_{2}-\mathrm{C}_{4}$ olefin selectivity and high $\mathrm{CO}$ conversion. However, the $\mathrm{K} / \mathrm{FeOx}$ catalyst, which was simply impregnated with a potassium promoter, showed a high resistance to catalyst attrition and high catalytic performance; this catalyst is potentially one of the best catalysts for MT-FTS reaction in a BFBR.

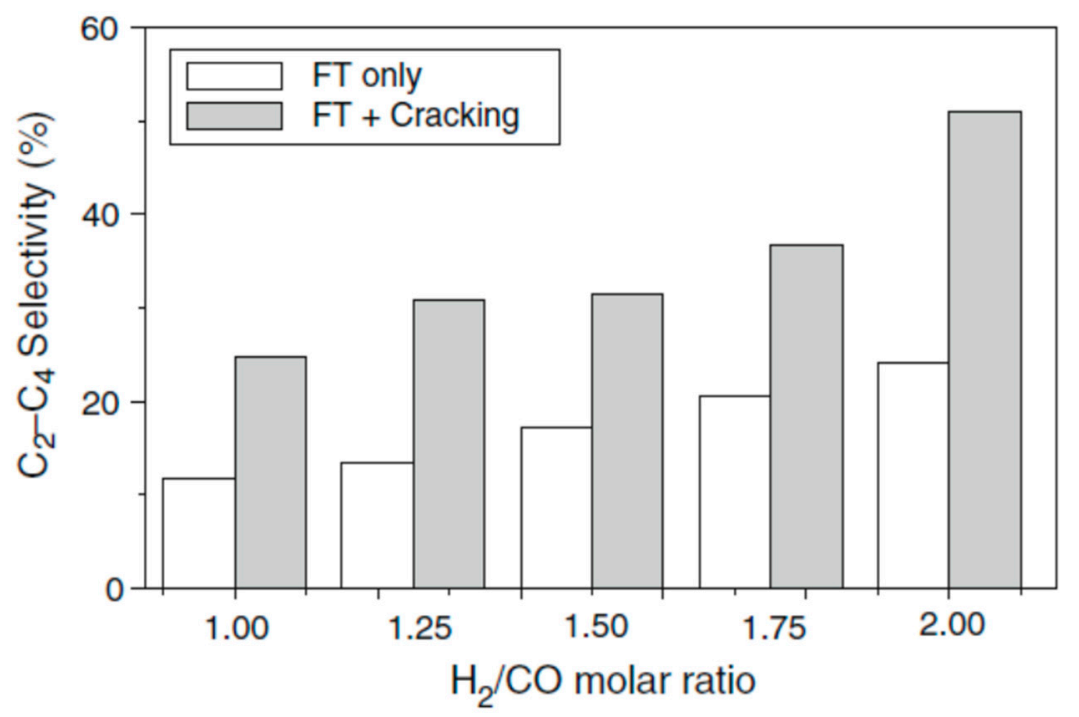

Figure 20. Effect of dual-bed system [110].

\subsection{Light Hydrocarbon}

Most of the research analyzed herein into the production of light hydrocarbons below $\mathrm{C}_{5}$ has focused on the production of liquefied petroleum gas (LPG)-class paraffin and olefin $\left(\mathrm{C}_{2}-\mathrm{C}_{4}\right)$. In the FTS reaction under a $\mathrm{H}_{2} / \mathrm{CO}$ ratio greater than 2.0, the methane selectivity increases, and the selectivity of paraffin to olefin increases; the catalysts used in these processes are typically a combination of $\mathrm{Co}$, $\mathrm{Fe}$, and Ni. Meanwhile, in the case of light-olefin production, $\mathrm{a}_{2} / \mathrm{CO}$ ratio of 2.0 is used, along with predominantly Fe catalysts.

It is noteworthy that researchers in Japan and South Korea, where natural gas is expensive, report their research on light hydrocarbon production. In the United States, Europe, and Iran, there is a great interest in producing middle distillates rather than light hydrocarbons. Because the standards, especially the calorific values, for domestic pipeline (natural gas) networks in Japan and South Korea differ from those in the USA and Europe, Japanese and South Korean researchers have focused on the production of high-calorific-value synthetic natural gas. Several related patents have been registered in Japan. A representative patent is that by the COSMO Company of Japan, who patented a catalyst containing $\mathrm{Ru}$ in an active $\mathrm{Al}_{2} \mathrm{O}_{3}$ support and the design of a reactor for manufacturing high-calorific synthetic natural gas. 


\subsubsection{Supported with Alumina or Silica Focused Olefin Production}

Since the 2000s, researchers in South Korean have reported numerous supported catalysts for olefin production. Researchers have focused particularly on the direct production of olefin light hydrocarbons from syngas. Hong et al. published the first study concerning the production of light hydrocarbons using $\mathrm{Fe}-\mathrm{Cu}-\mathrm{K}-\mathrm{Al}$ in 2001 [112]. Even though their study focused on the conversion from $\mathrm{CO}_{2}$, the catalytic performance was very low $\left(41.15 \% \mathrm{CO}_{2}\right.$ conversion), and the catalysts were deactivated by the growth of crystallites with increasing time-on-stream. In 2004, Jun et al. [113] reported that $\mathrm{Al}_{2} \mathrm{O}_{3}$ is a more suitable support material than $\mathrm{SiO}_{2}$ for $\mathrm{Fe}-\mathrm{Cu}-\mathrm{K}$ catalysts for the FTS from biomass-derived syngas, which consists of $\mathrm{CO}, \mathrm{CO}_{2}$, and $\mathrm{H}_{2}$ gases, because of the good dispersion of $\mathrm{Fe}, \mathrm{Cu}$, and $\mathrm{K}$ (as revealed by measurements of their BET surface area and chemisorption of $\mathrm{CO}_{2}$ and $\mathrm{H}_{2}$ ).

Lee et al. [110] and Park et al. [95] focused on the direct production of $C_{2}-C_{4}$ olefins from syngas using a dual reactor with $\mathrm{Fe}-\mathrm{Cu}-\mathrm{K}-\mathrm{Al}$ FTS catalysts and $\mathrm{H}-\mathrm{ZSM} 5$ cracking catalyst. They reported that the dual reactor system increased the $\mathrm{C}_{2}-\mathrm{C}_{4}$ selectivity at a $\mathrm{H}_{2} / \mathrm{CO}$ ratio between 1.0 and 2.0, and the alkalization of the Fe-based FTS catalysts promoted chain growth due to the formation of an $\mathrm{Fe}_{2} \mathrm{O}_{3}$ crystalline phase. As a result, Figure 21 shows an increase of the $\mathrm{C}_{2}-\mathrm{C}_{4}$ selectivity with increasing cracking temperature.

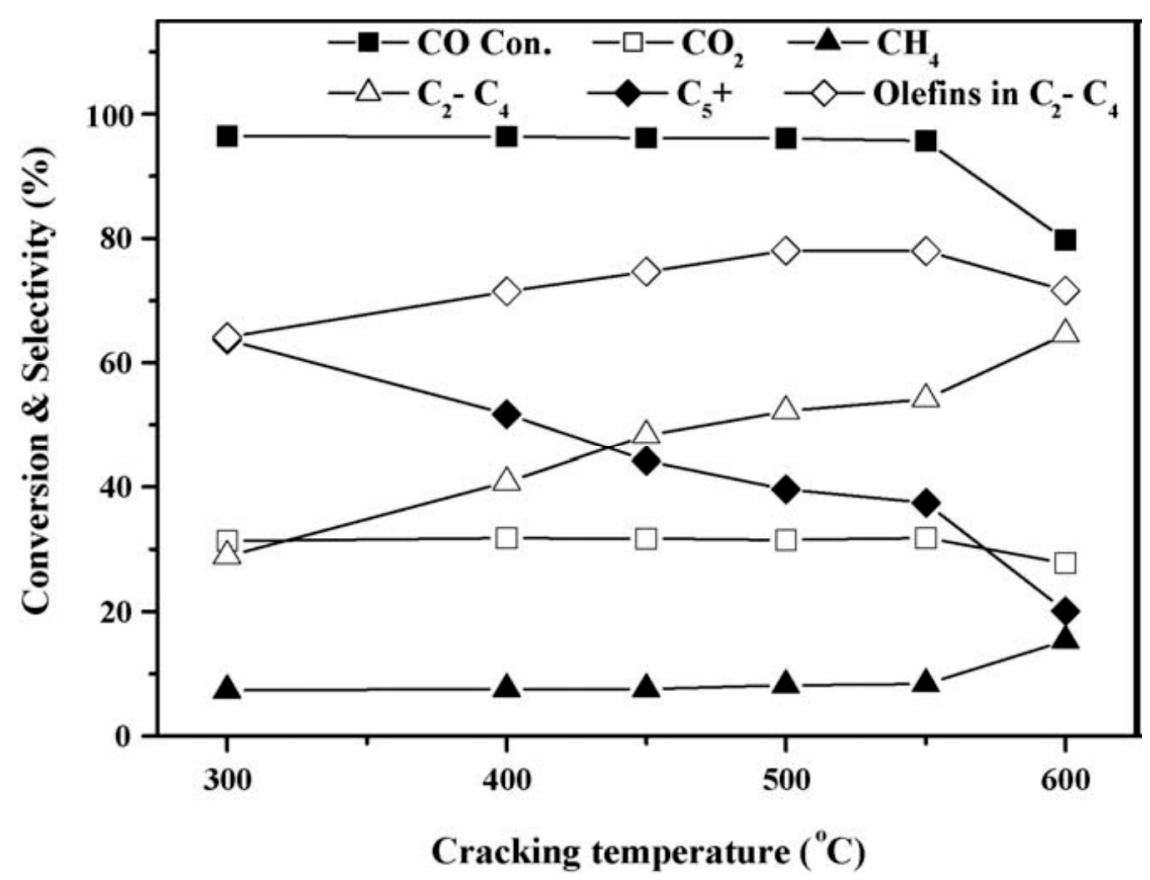

Figure 21. Effect of cracking reaction temperature on product selectivity. Reprinted with permission from [95]. Copyright (2009) Elsevier Science Inc., New York, America.

Kang et al. [114] reported the effect of the preparation method of $\mathrm{Fe}-\mathrm{Cu}-\mathrm{Al}$ catalysts promoted with K. They compared the performance of catalysts prepared by typical co-precipitation (CP), Sol-Gel (SG), typical wet-impregnation on alumina (WI), and co-precipitation on the slurry of $\mathrm{Al}_{2} \mathrm{O}_{3}$ (CPS). The highest $\mathrm{C}_{2}-\mathrm{C}_{4}$ olefin yield was $11.4 \%$ and was achieved with the SG catalyst, which exhibited the highest surface area and reducibility among the investigated catalysts. The SG catalyst maintained 95.5\% CO conversion at $\sim 70 \mathrm{~h}$, as shown in Figure 22. 


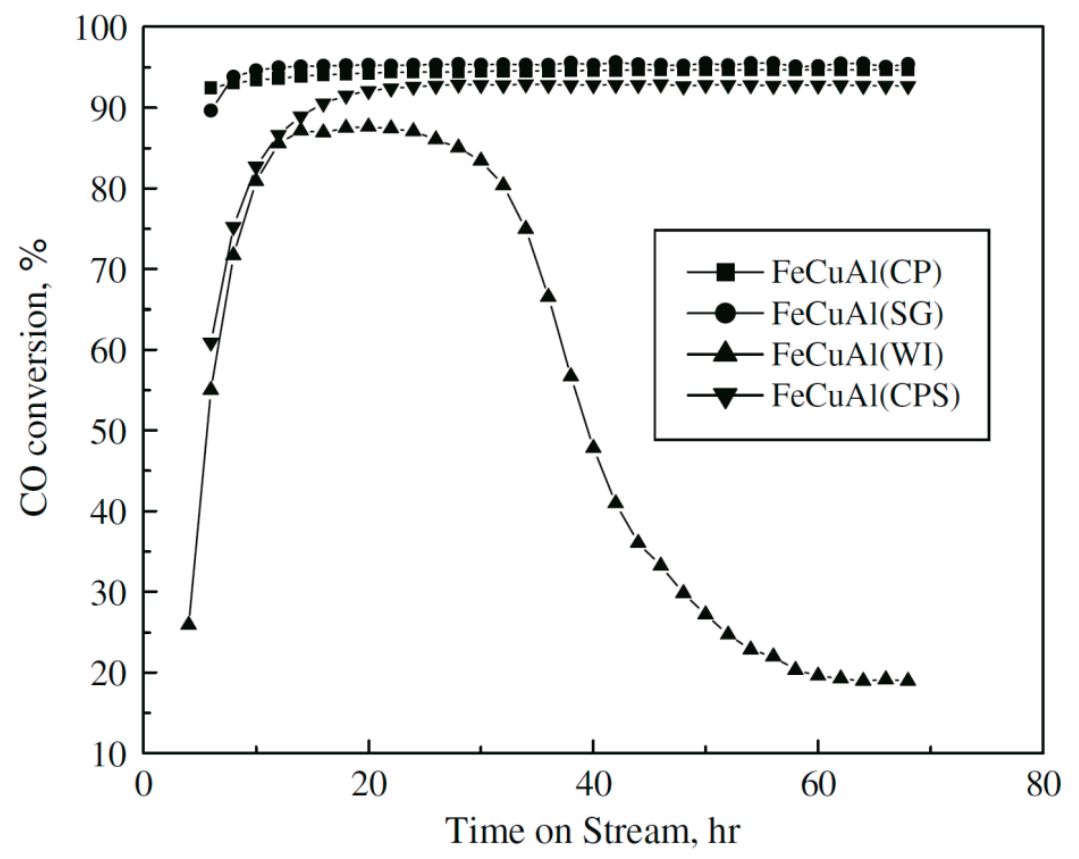

Figure 22. Activity variation of $\mathrm{Fe}-\mathrm{Cu}-\mathrm{Al}$ catalysts with time-on-stream [114].

Kang et al. [115] compared the FTS activities of catalysts prepared using different Fe precursors, including iron nitrate, iron chloride, and iron acetate, and $\mathrm{Al}_{2} \mathrm{O}_{3}$ and $\mathrm{SiO}_{2}$ supports. In this case, the $\mathrm{CO}$ conversion rate, the $\mathrm{CO}_{2}$ selectivity, and the $\mathrm{C}_{2}-\mathrm{C}_{4}$ formation rate were higher than those of $\mathrm{C}_{5}$ in the case where $\mathrm{Al}_{2} \mathrm{O}_{3}$ was used as a support rather than $\mathrm{SiO}_{2}$, which is advantageous in synthesizing light hydrocarbons. They found that the catalytic performance was correlated with X-ray photoelectron spectroscopy (XPS) analysis results ( $\left.I_{\mathrm{ads}}: 284.4 \mathrm{eV}, I_{\mathrm{dep}}: 288.2 \mathrm{eV}\right)$, as shown in Figure 23. The $\mathrm{C}_{2}-\mathrm{C}_{4}$ selectivity for the six evaluated catalysts was reported to be proportional to the intensity ratio $\left(I_{\text {dep }} / I_{\text {ads }}\right)$, which was attributed the effect of the production amount of iron carbide.

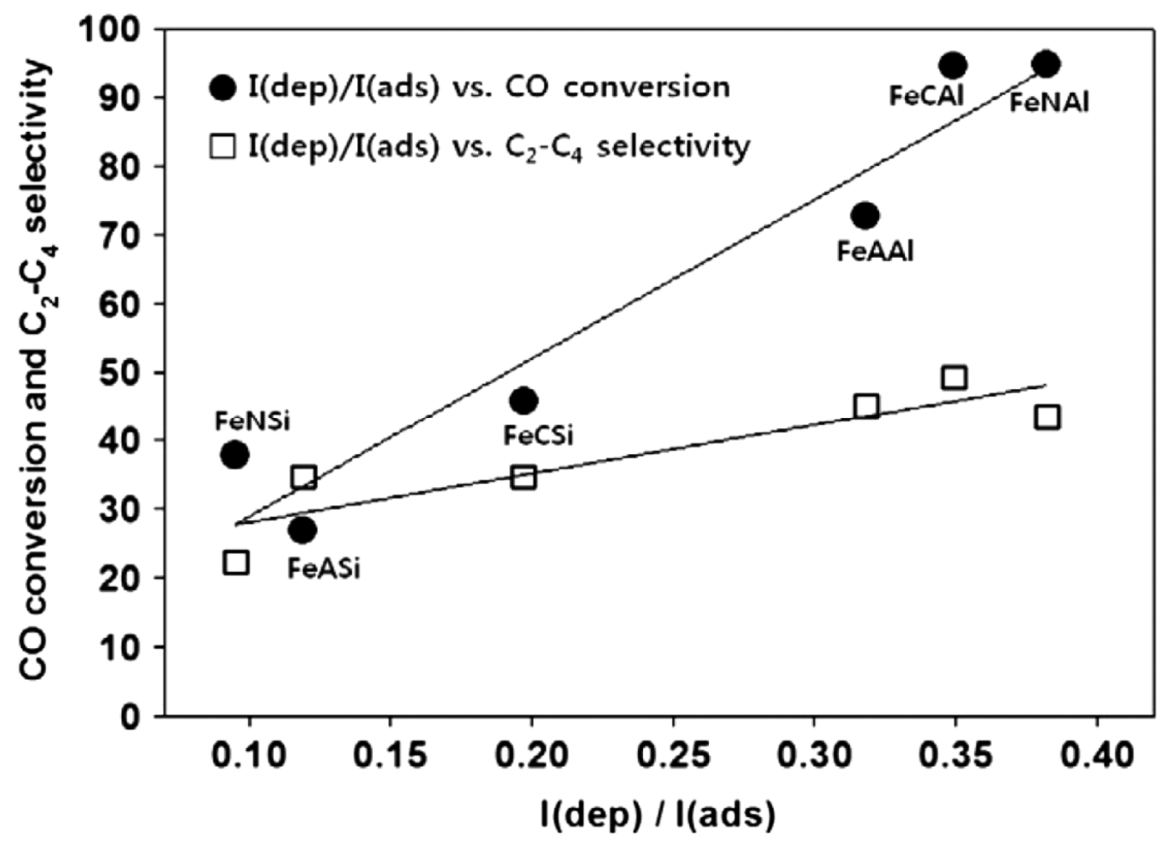

Figure 23. Correlation of catalytic performance with the intensity ratio from X-ray photoelectron spectroscopy (XPS) results. Reprinted with permission from [115]. Copyright (2013) Elsevier Science BV, Amsterdam, Netherlands. 
Kang et al. [111] compared the yields of light olefins obtained with Fe catalysts in a fixed bed reactor (FBR) and a bubbling fluidized bed reactor (BFBR). The light-olefin yield of $\mathrm{K} / \mathrm{FeCuAlOx}$ prepared by the co-precipitation method and that of the $\mathrm{K} / \mathrm{FeOx}$ catalyst prepared by the impregnation method both exceeded 20\%, as shown in Figure 24. Although not a result obtained during long-term operation, the BFBR was found to be advantageous for olefin production.

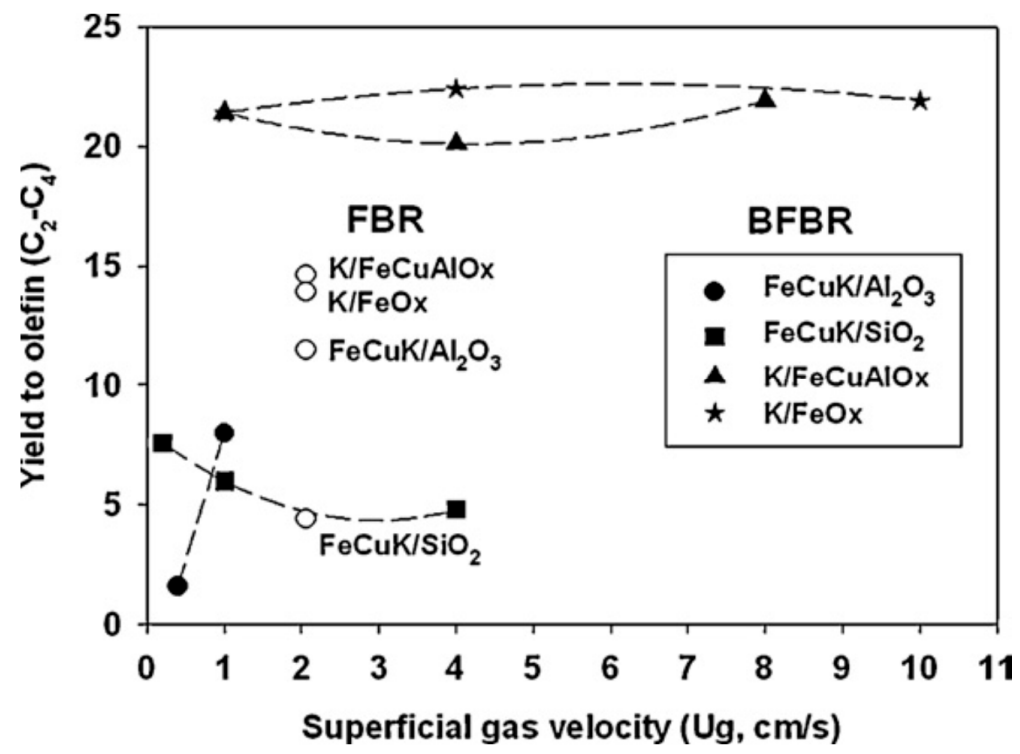

Figure 24. The yield to $\mathrm{C}_{2}-\mathrm{C}_{4}$ olefin with respect to the superficial gas velocity in a fixed bed reactor (FBR) and a bubbling fluidized bed reactor (BFBR). Reprinted with permission from [111]. Copyright (2011) Elsevier Science BV, Amsterdam, The Netherlands.

\subsubsection{Recent Advancements with Cracking Catalysts in South Korea}

As previously mentioned, in efforts to improve the selectivity toward $C_{2}-C_{4}$ hydrocarbons, improvements were achieved with zeolite-type cracking catalysts, which have acidic sites. In addition, the selectivity and the yield are determined by the composition as well as by the preparation method of the catalysts.

\subsection{Middle Distillates Production}

Researchers' interests in middle-distillates production differ markedly from their interests in light-hydrocarbon production because the middle distillates are related to gasoline and diesel fuel production from syngas in processes known as Biomass to Liquid (BTL), Coal to Liquid (CTL), or Gas to Liquid (GTL). However, little research has reported on the direct production of middle distillates $\left(\mathrm{C}_{5}-\mathrm{C}_{22}\right)$. [115]. Most of the literature concerns (i) the comparison of Fe- or Co-based catalysts with novel metal catalysts such as $\mathrm{Pt}, \mathrm{Pd}$, or $\mathrm{Rh}$ as an active component on $\mathrm{Al}_{2} \mathrm{O}_{3}$ or $\mathrm{SiO}_{2}$; (ii) physically mixed catalysts with zeolite for cracking reaction; (iii) impregnated catalysts on the zeolite prepared by specialized methods; and (iv) hybrid catalysts consisting of a cracking catalyst coated onto a Co-based catalyst. Some reports concern the production of hydrocarbons smaller than $\mathrm{C}_{12}$ using a catalyst on zeolite; however, few studies on the direct synthesis of $C_{5}-C_{22}$ hydrocarbons have been reported.

\subsubsection{ZSM Supported Co-Based Catalyst}

In South Korea, Kang et al. [116] prepared a Co/ZSM-5 catalyst on ZSM-5 as a support by impregnation to achieve direct middle-distillates production. They investigated the selectivity of $C_{5}-C_{9}$ hydrocarbons in the range of gasoline while changing operating temperature $\left(220^{\circ} \mathrm{C}\right.$ and $\left.240{ }^{\circ} \mathrm{C}\right)$ and using various ZSM- 5 catalysts with different $\mathrm{Si} / \mathrm{Al}$ ratios $(15,25,140$, and 250). As shown in Figure 25, the selectivity of $\mathrm{C}_{5}-\mathrm{C}_{9}$ tended to increase with increasing density of weak acid sites. 


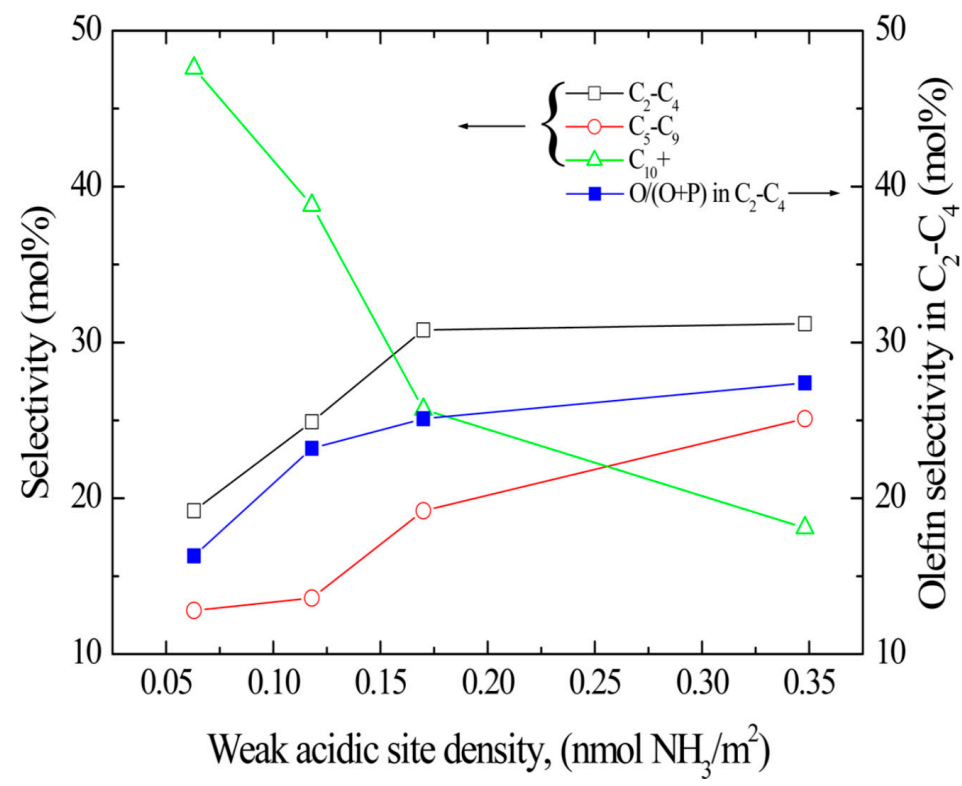

Figure 25. Correlation between the surface acidity and the selectivity of hydrocarbons. Reprinted with permission from [116]. Copyright (2011) Springer, New York, America.

Kang et al. [117] reported the activities of the modified $\mathrm{ZSM}-5 /\left(\mathrm{Co} / \mathrm{SiO}_{2}\right)$ catalyst with various ZSM-5 weight ratios to produce the middle distillates. As shown in Figure 26, even though the CO conversions were slightly decreased with increasing density of the acid point, the $C_{5}-C_{22}$ selectivity was not affected on the basis of the proposed mechanism (attributed to the formation of a small crystallite size of cobalt oxides by the adjacent contact of weak acidic sites of ZSM- 5 on the $\mathrm{Co} / \mathrm{SiO}_{2}$ surface). ZSM-5 particles with cobalt oxides can also enhance the extent of olefin cracking reaction of FTS products, and it increases the $C_{5}-C_{22}$ hydrocarbon selectivity, as shown in Figure 27. Kang et al. [118] also reported on the effect of a novel metal additive (Ru-nitrate, Pt-nitrate/chloride, and La-nitrate), as shown in Figure 28. Ryu et al. later investigated the FTS reaction performance using Co-based catalysts supported on ZSM-5 with Ru, Pt, and La as co-catalysts [119]. Compared with other promoters, $\mathrm{Pt}$ tended to show high $\mathrm{CO}$ conversion rates because of its excellent reducibility. Even strongly acidic sites showed no clear difference when the promoter was varied; however, the selectivity of $C_{5}-C_{9}$ was improved because of the strength of the weak acid points.

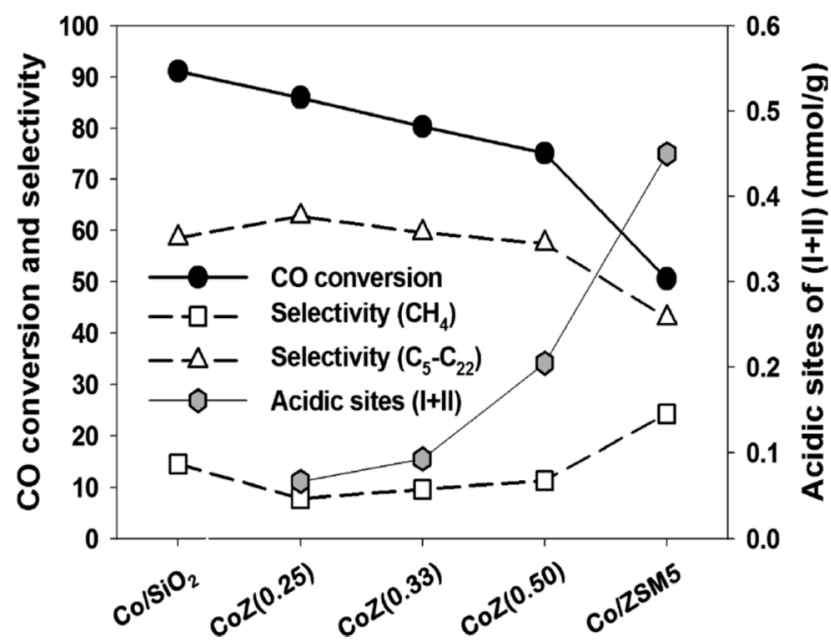

Figure 26. Catalytic performance (CO conversion and product distribution) with respect to the acid site density on the ZSM-5-modified $\mathrm{Co} / \mathrm{SiO}_{2}$ catalysts. Reprinted with permission from [117]. Copyright (2012) ACS, Washington, DC, America. 


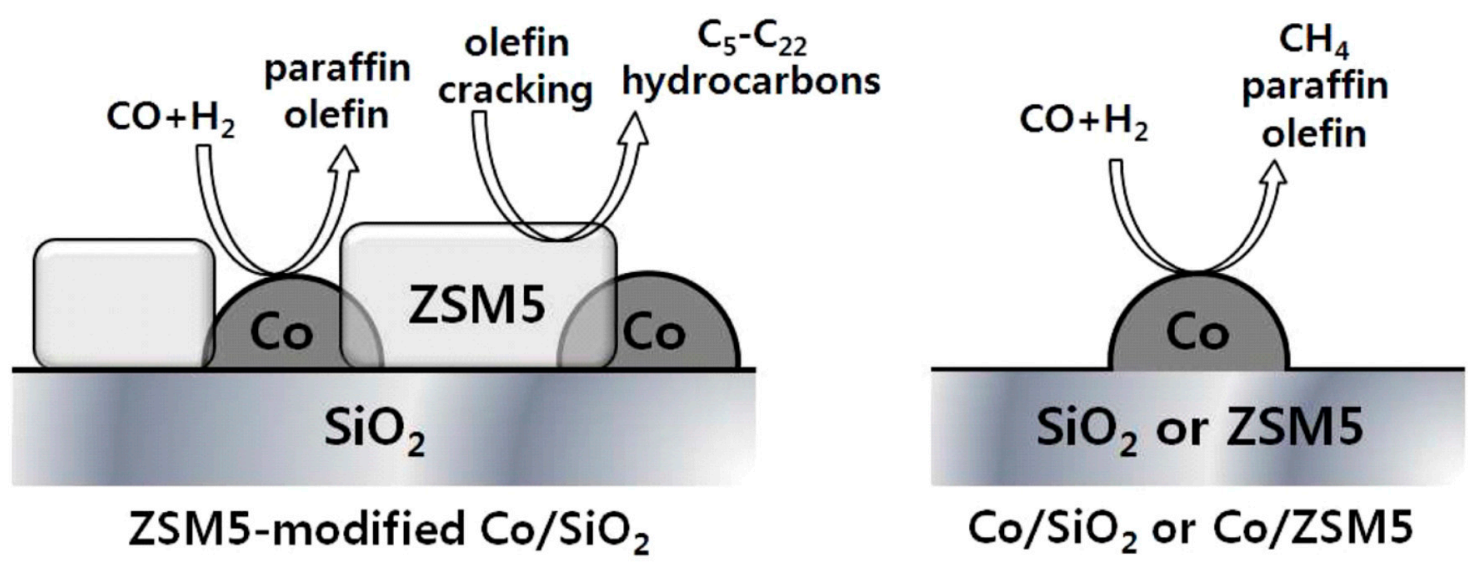

Figure 27. Schematic diagram of ZSM-5-modified $\mathrm{Co} / \mathrm{SiO}_{2}$ and impregnated cobalt-based catalysts. Reprinted with permission from [117]. Copyright (2012) ACS, Washington, DC, America.

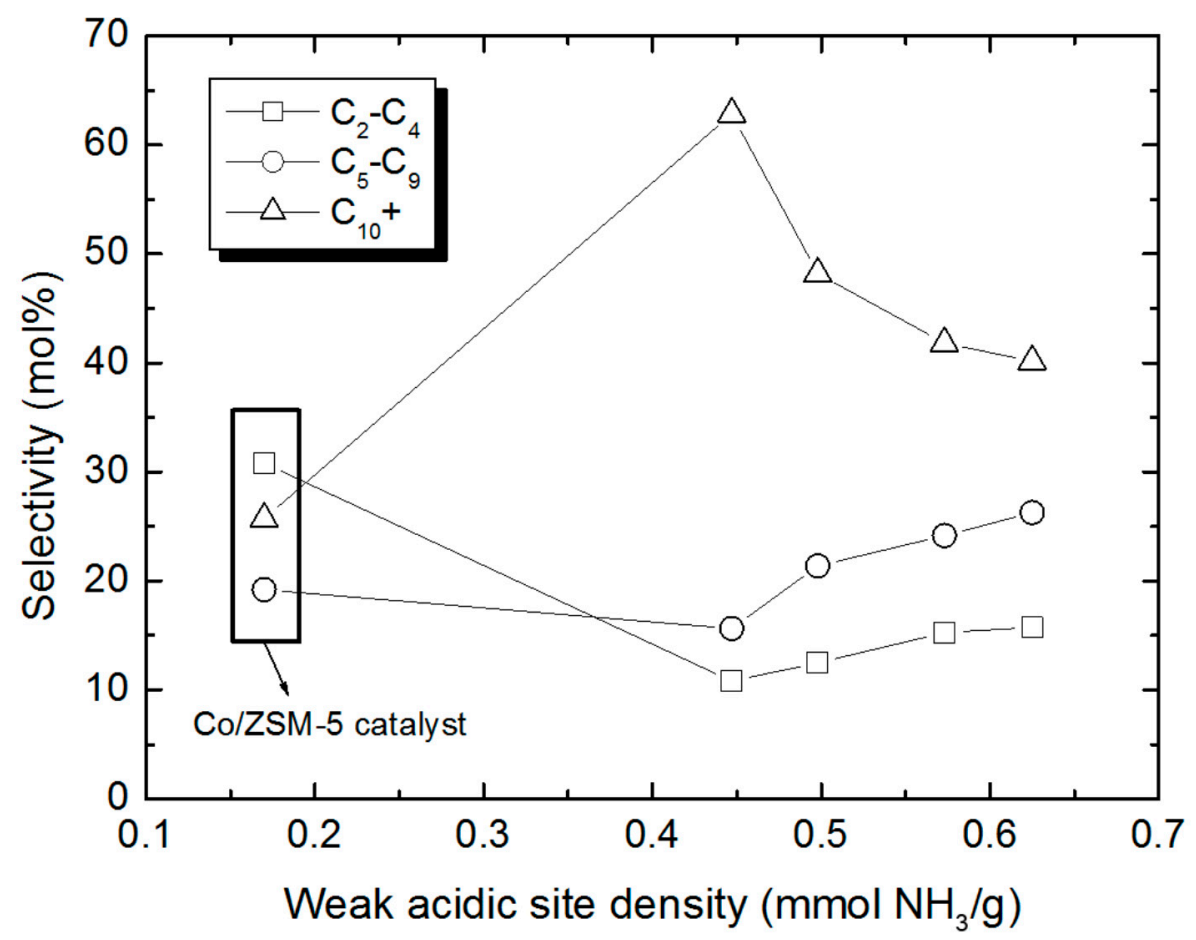

Figure 28. Effect of Promoter on the correlation between the surface activity and the selectivity of hydrocarbons. Reprinted with permission from [118].

Kang et al. [120] reported the optimal Pt content is $0.3 \mathrm{wt} \%$. They reported that, when the Pt content was increased, the $\mathrm{C}_{10}$ + selectivity increased. They attributed this behavior to the improvement in reducibility resulting from improved dispersion of the active material. On the basis of the aforementioned results, they concluded that the selectivity of the product in the $C_{5}-C_{9}$ range was determined by the density of the weak acid sites of the hybrid catalyst.

\subsubsection{KIT-6 Supported Catalysts}

Cho et al. [121] observed the FTS reaction characteristics and the structural characteristics of hybrid catalysts using a mixed oxide (Fe- $\mathrm{Zr}$ ) catalyst of $\mathrm{Fe}_{2} \mathrm{O}_{3}-\mathrm{ZrO}_{2}$ in mesoporous KIT-6 to produce intermediate fractions. The mixed catalyst was prepared with various $\mathrm{Zr} / \mathrm{Fe}$ ratios $(0.0,0.1,0.3,0.5$, and 1.0). The conversion to $\mathrm{CO}_{2}$ was high, but the $\mathrm{CO}$ conversion rate and the $\mathrm{C}_{5}+$ selectivity of $80 \%$ or more were higher. Cho et al. [122] investigated the FTS reaction and the structural characteristics of $\mathrm{Fe}_{2} \mathrm{O}_{3}$ catalysts as functions of the pore size of mesoporous KIT- 6 . The pore size was changed to 
$\sim 0.7 \mathrm{~nm}$ (M7), $\sim 5 \mathrm{~nm}$ (B5), $4 \mathrm{~nm}$ and $3.6 \mathrm{~nm}$ (B4), etc., and KFe/KIT-6 (B5) was used as a promoter with $2 \mathrm{wt} \%$ of $\mathrm{K}$ (potassium). The mesoporous size of the catalysts was found to affect the hydrocarbon conversion. The addition of a small amount of $\mathrm{K}$ as a promoter slightly increased $\mathrm{C}_{5}+$ selectivity, $\mathrm{CO}$ conversion, and olefin selectivity.

Park et al. [123] observed FTS reaction characteristics and structural characteristics of $\mathrm{Co}_{3} \mathrm{O}_{4}-\mathrm{Al}_{2} \mathrm{O}_{3}$ (mesopore-CoAl) catalysts prepared by the nano-casting method using a KIT-6 hard template. The mesoporous KIT- 6 catalyst affected hydrocarbon conversion and intermediate oil production depending on the phosphorus content. Among the developed catalysts, that with $0.3 \mathrm{wt} \%$ of $\mathrm{P}$ was reported to exhibit the best performance.

Cho et al. [124] prepared CoZrP/KIT-6 catalysts for the FTS reaction and studied their structural characteristics. The amounts of $\mathrm{P}$ in catalysts with $20 \mathrm{wt} \% \mathrm{Co}$ and $12 \mathrm{wt} \% \mathrm{Zr}$ were $0.1,0.2,0.6$, and $2 \mathrm{wt} \%$. They found that the mesoporous KIT- 6 catalyst affected hydrocarbon conversion and intermediate oil production depending on the phosphorus content. Compared with the FeZr-based catalysts studied previously, the catalyst with $0.1 \mathrm{wt} \% \mathrm{P}$ exhibited low CO conversion but improved $\mathrm{C}_{2}-\mathrm{C}_{4}$ selectivity.

\subsection{Recent Trend for the Catalysts Design}

The early FTS catalyst development in South Korea was reported in order to improve the dispersibility of $\mathrm{Fe}$ and $\mathrm{Co}$ or in order to improve the reducibility by adding various promoters and small amounts of novel metals to increase the productivity of the wax component. In particular, the support selection is very important for use in SBCR or fluidized bed, and the evaluation for the attrition test of the catalysts is also an important factor.

Recently, studies have reported producing light hydrocarbons and middle distillates in combination with acid catalysts to overcome the ASF distribution. Particularly, since the acid site control of the catalyst can be converted to light hydrocarbons or middle distillates by cracking heavy hydrocarbons produced in the FTS reaction, studies on combinations of acid catalysts such as alumina or zeolite and Fe- or Co-based catalysts (as FTS catalysts) have been reported.

It is noteworthy that various catalysts prepared by simple mixing, impregnation, co-precipitation, and hydrothermal synthesis using FTS and acid catalysts have been studied, and the focus was placed on improving the selectivity of the product by controlling the dispersibility of the FTS catalyst and the acid site of the hybrid catalyst.

Besides, from the reports of Ponec, Liu et al., Chen et al., and many other researchers, the FTS activity and selectivity are affected by the differences of particle size and crystal phase (e.g., FCC or HCP) as mentioned in Section 3.3. Thus, well-organized (size and shape) nano-manufacturing technology is one of the reasonable approaches to enhance activity and selectivity. In South Korea, there is some research related to zeolite supported catalysts and nano-sized active materials. However, there are no approaches related to well-organized shaped catalysts. With advances in nano-level manufacturing technologies, some studies related to the design of novel catalysts have recently been reported in South Korea. Choi et al. [125] introduced a $9 \mathrm{~nm} \mathrm{Pt}-\mathrm{Ni}$ octahedral catalyst for the oxygen reduction reaction (ORR), which is a rate-determining step of fuel cell reactions. As shown in Figure 29, the catalytic activity was extremely increased when well-defined $\mathrm{Pt}-\mathrm{Ni}$ catalysts prepared with nano-level manufacturing technologies were used. In addition, Park et al. [126] reported the PtCu@PtCuNi dendrite@frame nano-catalysts for the oxygen reduction reaction. As shown in Figure 30, the ORR catalysts exhibited a well-defined shape and size and extremely good stability, maintaining their activity for 5000 cycles in an $\mathrm{O}_{2}$-saturated $0.1 \mathrm{M}$ aqueous $\mathrm{HClO}_{4}$ solution. Although these studies are in fields (for fuel cells and water electrolysis) unrelated to FTS, if these nano-level manufacturing technologies are collaborating with the FTS catalyst design, this would be promising from the perspective of catalyst design in South Korea. 

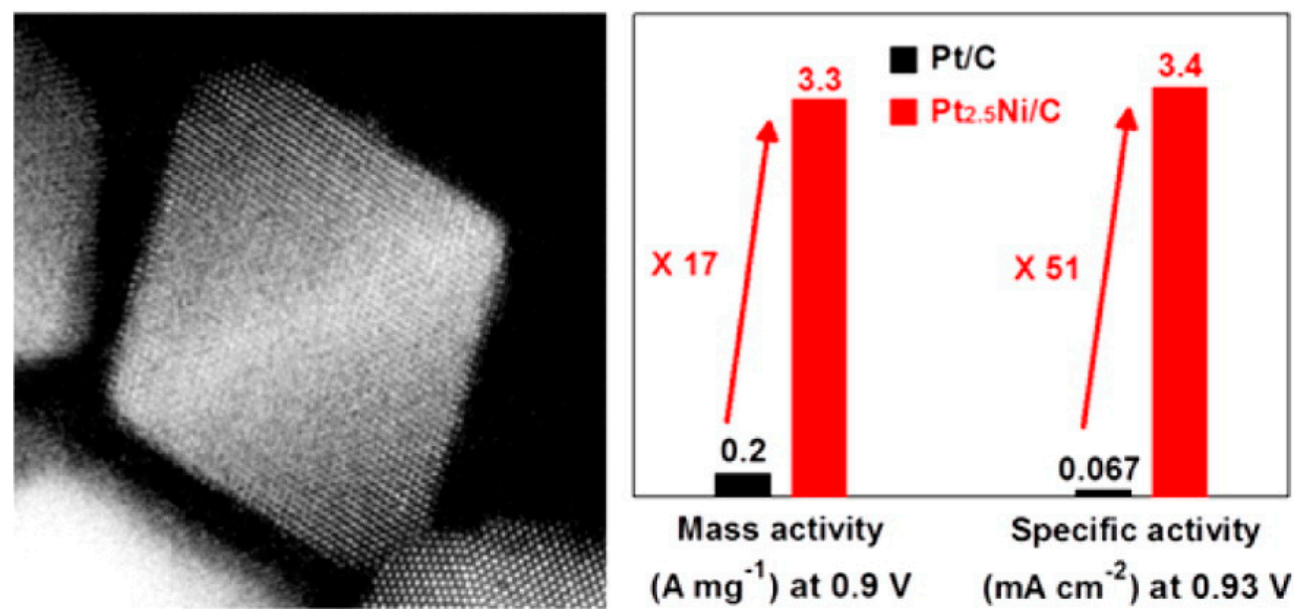

Figure 29. High-angle annular dark-field scanning transmission electron microscopy (HAADF-STEM) image of the octahedral $\mathrm{Pt}-\mathrm{Ni}$ with $9 \mathrm{~nm}$ edge length (left) and the comparison of $\mathrm{Pt}$ mass and specific activity of $\mathrm{Pt} / \mathrm{C}$ and octahedral $\mathrm{Pt} 2.5 \mathrm{Ni} / \mathrm{C}$ (right). Reprinted with permission from [125]. Copyright (2013) ACS, Washington, DC, America.

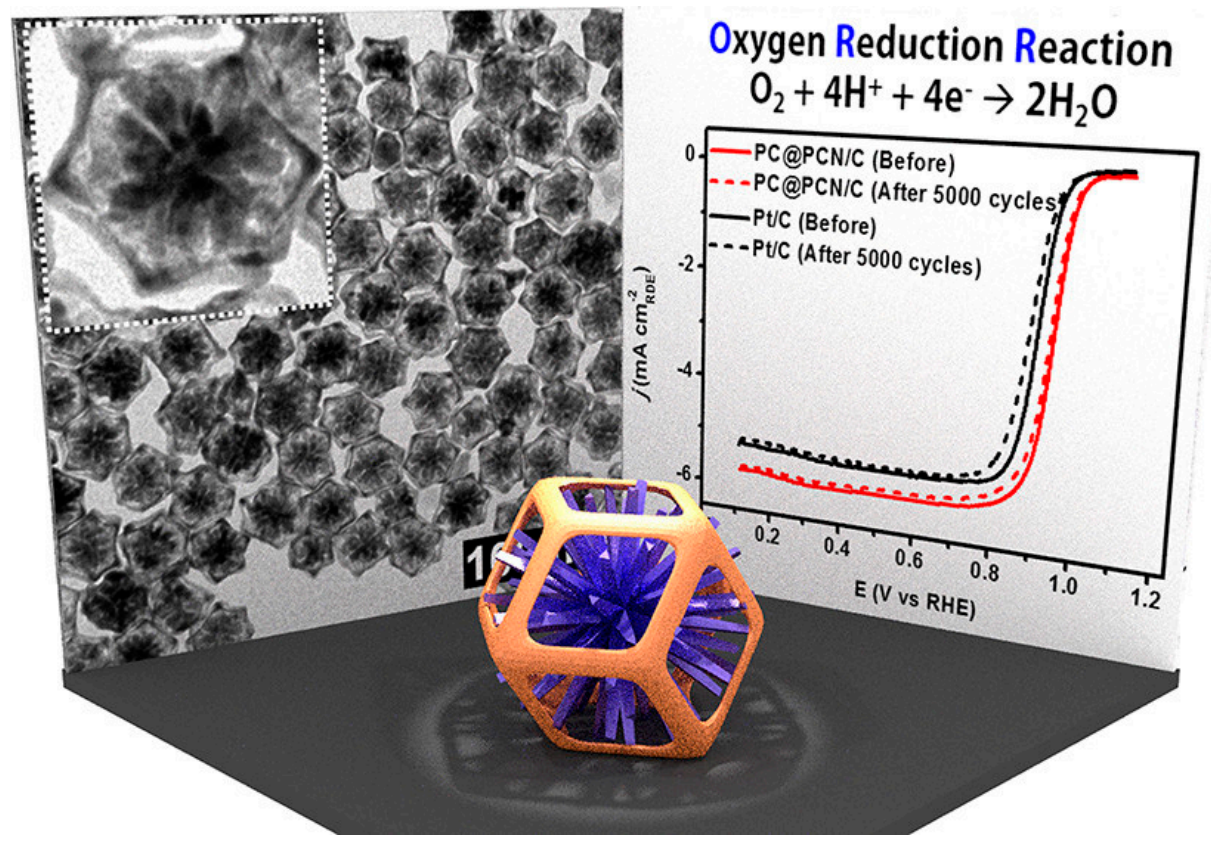

Figure 30. High-angle annular dark-field scanning transmission electron microscopy (HAADF-STEM) image of PC@PCN, oxygen reduction reaction (ORR) polarization curves of PC@PCN/C and commercial $\mathrm{Pt} / \mathrm{C}$ before and after the cycling test for 5000 cycles, and the schematic illustration of PC@PCN Dendrite@frame Reprinted with permission from [126]. Copyright (2017) ACS, Washington, DC, America.

\section{Conclusions}

In this review, we surveyed typical and recent technologies related to FTS catalyst design for the production of light hydrocarbons and middle distillates. Catalysts with high CO conversion and selectivity require well-designed components (e.g., active material, promoter, and support). Some studies with enhanced catalytic design technologies, including hybrid catalysts, encapsulated core-shell catalysts, and well-organized catalysts were summarized. In South Korea, various Fe and Co catalysts have been developed to improve the selectivity of light hydrocarbons and middle distillates from syngas. In most cases, the activity of catalysts and the selectivity of products were compared on 
the basis of the addition of a promoter, the preparation method, and the support material (e.g., $\mathrm{Al}_{2} \mathrm{O}_{3}$, $\mathrm{SiO}_{2}$, zeolites, and their combinations).

For the development of catalysts suitable for commercial-scale FTS processes, further studies concerning mass production technology to improve the physical properties of the developed catalysts and a suitable reactor design to maximize the lifetime of the catalysts are necessary. There were many kinds of research in FTS catalyst design in South Korea, but some engineering data were not confirmed on a commercial-scale, which include the reactor type (packed bed, slurry bobble column, fluidized bed, etc.), the reactor design (adiabatic, shell and tube, micro channel reactor, etc.), and other engineering data (temperature control, process flow diagram, recycle ratio, etc.). The engineering data strictly affect the catalytic performances, and the types of the reactor design affect the catalyst lifetime (which is affected by physical and chemical strength of the catalysts). There were simply no acceptable catalytic-only performances (e.g., $\mathrm{CO}$ conversion, $\mathrm{C}_{2}-\mathrm{C}_{4}$ selectivity, etc.) in the commercial scale FTS process. From an academic perspective, the fusion of typical FTS catalyst design technology with nano-level manufacturing technologies will greatly advance FTS catalyst design, though it involves high catalyst cost, hard to mass production, and complicated preparing methods.

Author Contributions: Conceptualization, H.J.C., J.-H.K. and S.C.L.; Supervision, S.-H.K., J.C.K., and M.-J.P.; Writing-original draft, H.J.C. (Sections 1, 3 and 5), J.-H.K. (Sections 2 and 4); Writing-review and editing, S.C.L., S.-H.K.; Formal analysis and investigation, H.-S.K., S.B.J., J.-H.R.; Data curation and draft preparation, T.Y.K., C.H.L., and S.J.K. All authors have read and agreed to the published version of the manuscript.

Funding: This work was supported by the Korea Institute of Energy Technology Evaluation and Planning (KETEP) grant funded by the Ministry of Trade, Industry \& Energy (MOTIE) of the Republic of Korea (No.20173010050110). This research was supported by Basic Science Research Program through the National Research Foundation of Korea (NRF) funded by the Ministry of Education (NRF-2019R1A6A3A01096215).

Conflicts of Interest: The authors declare no conflict of interest.

\section{References}

1. Hernández, S.; Amin Farkhondehfal, M.; Sastre, F.; Makkee, M.; Saracco, G.; Russo, N. Syngas Production from Electrochemical Reduction of $\mathrm{CO}_{2}$ : Current Status and Prospective Implementation. Green Chem. 2017, 19, 2326-2346. [CrossRef]

2. de Smit, E.; Weckhuysen, B.M. The renaissance of iron-based Fischer-Tropsch synthesis: On the multifaceted catalyst deactivation behaviour. Chem. Soc. Rev. 2008, 37, 2758-2781. [CrossRef] [PubMed]

3. Kim, H.S.; Kim, J.H.; Kang, S.H.; Ryu, J.H.; Yang, H.C.; Chung, D.Y. Recent trends for temperature control technology of catalytic reaction processes accompanied the exothermic reaction from syngas. J. Energy Clim. Chang. 2015, 10, 133-164.

4. Schaidle, J.A.; Thompson, L.T. Fischer-Tropsch synthesis over early transition metal carbides and nitrides: CO activation and chain growth. J. Catal. 2015, 329, 325-334. [CrossRef]

5. Turner, M.L.; Long, H.C.; Shenton, A.; Byers, P.K.; Maitlis, P.M. The Alkenyl Mechanism for Fischer-Tropsch Surface Methylene Polymerisation; the Reactions of Vinylic Probes with $\mathrm{CO} / \mathrm{H}_{2}$ over Rhodium Catalyst. Chem. A Eur. J. 1995, 1, 549-556. [CrossRef]

6. Donnelly, T.J.; Yates, I.C.; Satterfield, C.N. Analysis and prediction of product distributions of the Fischer-Tropsch synthesis. Energy Fuels 1988, 2, 734-739. [CrossRef]

7. James, O.O.; Chowdhury, B.; Mesubi, M.A.; Maity, S. Reflections on the chemistry of the Fischer-Tropsch synthesis. RSC Adv. 2012, 2, 7347. [CrossRef]

8. Bian, G.; Oonuki, A.; Koizumi, N.; Nomoto, H.; Yamada, M. Studies with a precipitated iron Fischer-Tropsch catalyst reduced by $\mathrm{H}_{2}$ or CO. J. Mol. Catal. A Chem. 2002, 186, 203-213. [CrossRef]

9. Park, S.J. Fischer-Tropsch Synthesis on Fe-Cu-K/Zeolite for the Production of Light Olefins. Master. Thesis, Chungnam National University, Daejeon, Korea, 2009.

10. Bartholomew, C.H.; Farrauto, R.J. Fundamentals of Industrial Catalytic Processes; John Wiley \& Sons: Hoboken, NJ, USA, 2010.

11. Ponec, V. Active centres for synthesis gas reactions. Catal. Today 1992, 12, 227-254. [CrossRef] 
12. Perego, C.; Bortolo, R.; Zennaro, R. Gas to liquids technologies for natural gas reserves valorization: The Eni experience. Catal. Today 2009, 142, 9-16. [CrossRef]

13. James, O.O.; Mesubi, A.M.; Ako, T.C.; Maity, S. Increasing carbon utilization in Fischer-Tropsch synthesis using $\mathrm{H}_{2}$-deficient or $\mathrm{CO}_{2}$-rich syngas feeds. Fuel Process. Technol. 2010, 91, 136-144. [CrossRef]

14. Jahangiri, H.; Bennett, J.; Mahjoubi, P.; Wilson, K.; Gu, S. A review of advanced catalyst development for Fischer-Tropsch synthesis of hydrocarbons from biomass derived syn-gas. Catal. Sci. Technol. 2014, 4, 2210-2229. [CrossRef]

15. Schulz, H. Short history and present trends of Fischer-Tropsch synthesis. Appl. Catal. A Gen. 1999, 186, 3-12. [CrossRef]

16. Khodakov, A.Y.; Chu, W.; Fongarland, P. Advances in the Development of Novel Cobalt Fischer-Tropsch Catalysts for Synthesis of Long-Chain Hydrocarbons and Clean Fuels. Chem. Rev. 2007, 107, 1692-1744. [CrossRef] [PubMed]

17. Feyzi, M.; Irandoust, M.; Mirzaei, A.A. Effects of promoters and calcination conditions on the catalytic performance of iron-manganese catalysts for Fischer-Tropsch synthesis. Fuel Process. Technol. 2011, 92, 1136-1143. [CrossRef]

18. Yang, Y.; Xiang, H.W.; Xu, Y.Y.; Bai, L.; Li, Y.W. Effect of potassium promoter on precipitated iron-manganese catalyst for Fischer-Tropsch synthesis. Appl. Catal. A Gen. 2004, 266, 181-194. [CrossRef]

19. Ngantsoue-Hoc, W.; Zhang, Y.; O’Brien, R.J.; Luo, M.; Davis, B.H. Fischer-Tropsch synthesis: Activity and selectivity for Group I alkali promoted iron-based catalysts. Appl. Catal. A Gen. 2002, 236, 77-89. [CrossRef]

20. Lohitharn, N.; Goodwin, J.G. Effect of K promotion of Fe and FeMn Fischer-Tropsch synthesis catalysts: Analysis at the site level using SSITKA. J. Catal. 2008, 260, 7-16. [CrossRef]

21. Bai, L.; Xiang, H.; Li, Y.; Han, Y.; Zhong, B. Slurry phase Fischer-Tropsch synthesis over manganese-promoted iron ultrafine particle catalyst. Fuel 2002, 81, 1577-1581. [CrossRef]

22. Liu, Y.; Teng, B.T.; Guo, X.H.; Li, Y.; Chang, J.; Tian, L.; Hao, X.; Wang, Y.; Xiang, H.W.; Xu, Y.Y.; et al. Effect of reaction conditions on the catalytic performance of Fe-Mn catalyst for Fischer-Tropsch synthesis. J. Mol. Catal. A Chem. 2007, 272, 182-190. [CrossRef]

23. Lohitharn, N.; Goodwin, J.G. Impact of Cr, Mn and Zr addition on Fe Fischer-Tropsch synthesis catalysis: Investigation at the active site level using SSITKA. J. Catal. 2008, 257, 142-151. [CrossRef]

24. Li, J.; Jacobs, G.; Zhang, Y.; Das, T.; Davis, B.H. Fischer-Tropsch synthesis: Effect of small amounts of boron, ruthenium and rhenium on $\mathrm{Co} / \mathrm{TiO}_{2}$ catalysts. Appl. Catal. A Gen. 2002, 223, 195-203. [CrossRef]

25. Das, T.K.; Jacobs, G.; Patterson, P.M.; Conner, W.A.; Li, J.; Davis, B.H. Fischer-Tropsch synthesis: Characterization and catalytic properties of rhenium promoted cobalt alumina catalysts. Fuel 2003, 82, 805-815. [CrossRef]

26. Haddad, G.J.; Chen, B.; Goodwin, J.G., Jr. Characterization of $\mathrm{La}^{3+}$-Promoted $\mathrm{Co} / \mathrm{SiO}_{2}$ Catalysts. J. Catal. 1996, 160, 43-51. [CrossRef]

27. Sartipi, S.; Makkee, M.; Kapteijn, F.; Gascon, J. Catalysis engineering of bifunctional solids for the one-step synthesis of liquid fuels from syngas: A review. Catal. Sci. Technol. 2014, 4, 893-907. [CrossRef]

28. Jacobs, G.; Ma, W.; Davis, B. Influence of Reduction Promoters on Stability of Cobalt/g-Alumina Fischer-Tropsch Synthesis Catalysts. Catalysts 2014, 4, 49-76. [CrossRef]

29. Soled, S.; Iglesia, E.; Fiato, R.A. Activity and selectivity control in iron catalyzed Fischer-Tropsch synthesis. Catal. Lett. 1991, 7, 271-280. [CrossRef]

30. Raje, A.P.; O'Brien, R.J.; Davis, B.H. Effect of Potassium Promotion on Iron-Based Catalysts for Fischer-Tropsch Synthesis. J. Catal. 1998, 180, 36-43. [CrossRef]

31. Dinse, A.; Aigner, M.; Ulbrich, M.; Johnson, G.R.; Bell, A.T. Effects of Mn promotion on the activity and selectivity of $\mathrm{Co} / \mathrm{SiO}_{2}$ for Fischer-Tropsch Synthesis. J. Catal. 2012, 288, 104-114. [CrossRef]

32. Moradi, G.R.; Basir, M.M.; Taeb, A.; Kiennemann, A. Promotion of $\mathrm{Co} / \mathrm{SiO}_{2}$ Fischer-Tropsch catalysts with zirconium. Catal. Commun. 2003, 4, 27-32. [CrossRef]

33. Chen, H.; Adesina, A.A. Improved alkene selectivity in carbon monoxide hydrogenation over silica supported cobalt-molybdenum catalyst. Appl. Catal. A Gen. 1994, 112, 87-103. [CrossRef]

34. Jacobs, G.; Das, T.K.; Zhang, Y.; Li, J.; Racoillet, G.; Davis, B.H. Fischer-Tropsch synthesis: Support, loading, and promoter effects on the reducibility of cobalt catalysts. Appl. Catal. A Gen. 2002, 233, 263-281. [CrossRef]

35. Jacobs, G.; Chaney, J.A.; Patterson, P.M.; Das, T.K.; Davis, B.H. Fischer-Tropsch synthesis: Study of the promotion of Re on the reduction property of $\mathrm{Co} / \mathrm{Al}_{2} \mathrm{O}_{3}$ catalysts by in situ EXAFS/XANES of Co K and Re L III edges and XPS. Appl. Catal. A Gen. 2004, 264, 203-212. [CrossRef] 
36. Morales, F.; de Groot, F.M.F.; Gijzeman, O.L.J.; Mens, A.; Stephan, O.; Weckhuysen, B.M. Mn promotion effects in $\mathrm{Co} / \mathrm{TiO}_{2}$ Fischer-Tropsch catalysts as investigated by XPS and STEM-EELS. J. Catal. 2005, 230, 301-308. [CrossRef]

37. Das, D.; Ravichandran, G.; Chakrabarty, D.K. Synthesis of light alkenes from syngas on silicalite-1 supported cobalt and cobalt-manganese catalysts. Appl. Catal. A Gen. 1995, 131, 335-345. [CrossRef]

38. Lohitharn, N.; Goodwin, J.G.; Lotero, E. Fe-based Fischer-Tropsch synthesis catalysts containing carbide-forming transition metal promoters. J. Catal. 2008, 255, 104-113. [CrossRef]

39. Jalama, K.; Coville, N.; Hildebrandt, D.; Glasser, D.; Jewell, L.; Anderson, J.; Taylor, S.; Enache, D.; Hutchings, G. Effect of the addition of $\mathrm{Au}$ on $\mathrm{Co} / \mathrm{TiO}_{2}$ catalyst for the Fischer-Tropsch reaction. Top. Catal. 2007, 44, 129-136. [CrossRef]

40. Tavasoli, A.; Irani, M.; Abbaslou, R.M.M.; Trépanier, M.; Dalai, A.K. Morphology and deactivation behaviour of $\mathrm{Co}-\mathrm{Ru} / \gamma-\mathrm{Al}_{2} \mathrm{O}_{3}$ Fischer-Tropsch synthesis catalyst. Can. J. Chem. Eng. 2008, 86, 1070-1080. [CrossRef]

41. Li, J.; Corma, A.; Yu, J. Synthesis of new zeolite structures. Chem. Soc. Rev. 2015, 44, 7112-7127. [CrossRef]

42. Xiong, H.; Zhang, Y.; Liew, K.; Li, J. Ruthenium promotion of Co/SBA-15 catalysts with high cobalt loading for Fischer-Tropsch synthesis. Fuel Process. Technol. 2009, 90, 237-246. [CrossRef]

43. Wang, S.; Yin, Q.; Guo, J.; Ru, B.; Zhu, L. Improved Fischer-Tropsch synthesis for gasoline over Ru, Ni promoted Co/HZSM-5 catalysts. Fuel 2013, 108, 597-603. [CrossRef]

44. Chan, F.L.; Tanksale, A. Review of recent developments in Ni-based catalysts for biomass gasification. Renew. Sustain. Energy Rev. 2014, 38, 428-438. [CrossRef]

45. Reuel, R.C.; Bartholomew, C.H. Effects of support and dispersion on the CO hydrogenation activity/selectivity properties of cobalt. J. Catal. 1984, 85, 78-88. [CrossRef]

46. Kreitman, K.M.; Baerns, M.; Butt, J.B. Manganese-oxide-supported iron Fischer-Tropsch synthesis catalysts: Physical and catalytic characterization. J. Catal. 1987, 105, 319-334. [CrossRef]

47. Zwart, J.; Vink, J. Fischer-tropsch synthesis using zeolite-supported iron catalysts derived from iron carbonyl complexes. Appl. Catal. 1987, 33, 383-393. [CrossRef]

48. Pham, H.N.; Viergutz, A.; Gormley, R.J.; Datye, A.K. Improving the attrition resistance of slurry phase heterogeneous catalysts. Powder Technol. 2000, 110, 196-203. [CrossRef]

49. Khodakov, A.Y.; Griboval-Constant, A.; Bechara, R.; Villain, F. Pore-Size Control of Cobalt Dispersion and Reducibility in Mesoporous Silicas. J. Phys. Chem. B 2001, 105, 9805-9811. [CrossRef]

50. Panpranot, J.; Goodwin, J.G.; Sayari, A. Synthesis and characteristics of MCM-41 supported CoRu catalysts. Catal. Today 2002, 77, 269-284. [CrossRef]

51. Cagnoli, M.V.; Gallegos, N.G.; Alvarez, A.M.; Bengoa, J.F.; Yeramián, A.A.; Schmal, M.; Marchetti, S.G. Catalytic CO hydrogenation on potassic Fe/zeolite LTL. Appl. Catal. A Gen. 2002, 230, 169-176. [CrossRef]

52. Soled, S.; Iglesia, E.; Fiato, R.; Baumgartner, J.; Vroman, H.; Miseo, S. Control of Metal Dispersion and Structure by Changes in the Solid-State Chemistry of Supported Cobalt Fischer-Tropsch Catalysts. Top. Catal. 2003, 26, 101-109. [CrossRef]

53. Bahome, M.C.; Jewell, L.L.; Hildebrandt, D.; Glasser, D.; Coville, N.J. Fischer-Tropsch synthesis over iron catalysts supported on carbon nanotubes. Appl. Catal. A Gen. 2005, 287, 60-67. [CrossRef]

54. Spadaro, L.; Arena, F.; Granados, M.L.; Ojeda, M.; Fierro, J.L.G.; Frusteri, F. Metal-support interactions and reactivity of $\mathrm{Co} / \mathrm{CeO}_{2}$ catalysts in the Fischer-Tropsch synthesis reaction. J. Catal. 2005, 234, 451-462. [CrossRef]

55. Tavasoli, A.; Sadagiani, K.; Khorashe, F.; Seifkordi, A.A.; Rohani, A.A.; Nakhaeipour, A. Cobalt supported on carbon nanotubes-A promising novel Fischer-Tropsch synthesis catalyst. Fuel Process. Technol. 2008, 89, 491-498. [CrossRef]

56. Dacquin, J.; Dhainaut, J.; Duprez, D.; Royer, S.; Lee, A.F.; Wilson, K. An efficient route to highly organized, tunable macroporous-mesoporous alumina. J. Am. Chem. Soc. 2009, 131, 12896-12897. [CrossRef]

57. Ghampson, I.T.; Newman, C.; Kong, L.; Pier, E.; Hurley, K.D.; Pollock, R.A.; Walsh, B.R.; Goundie, B.; Wright, J.; Wheeler, M.C.; et al. Effects of pore diameter on particle size, phase, and turnover frequency in mesoporous silica supported cobalt Fischer-Tropsch catalysts. Appl. Catal. A Gen. 2010, 388, 57-67. [CrossRef]

58. Dhainaut, J.; Dacquin, J.; Lee, A.F.; Wilson, K. Hierarchical macroporous-mesoporous SBA-15 sulfonic acid catalysts for biodiesel synthesis. Green Chem. 2010, 12, 296. [CrossRef]

59. Malek Abbaslou, R.M.; Soltan, J.; Dalai, A.K. Iron catalyst supported on carbon nanotubes for Fischer-Tropsch synthesis: Effects of Mo promotion. Fuel 2011, 90, 1139-1144. [CrossRef] 
60. Pirez, C.; Caderon, J.; Dacquin, J.; Lee, A.F.; Wilson, K. Tunable KIT-6 Mesoporous Sulfonic Acid Catalysts for Fatty Acid Esterification. ACS Catal. 2012, 2, 1607-1614. [CrossRef]

61. Jung, J.; Kim, S.W.; Moon, D.J. Fischer-Tropsch Synthesis over cobalt based catalyst supported on different mesoporous silica. Catal. Today 2012, 185, 168-174. [CrossRef]

62. Arsalanfar, M.; Mirzaei, A.A.; Bozorgzadeh, H.R.; Samimi, A.; Ghobadi, R. Effect of support and promoter on the catalytic performance and structural properties of the Fe-Co-Mn catalysts for Fischer-Tropsch synthesis. J. Ind. Eng. Chem. 2014, 20, 1313-1323. [CrossRef]

63. Khodakov, A.Y. Fischer-Tropsch synthesis: Relations between structure of cobalt catalysts and their catalytic performance. Catal. Today 2009, 144, 251-257. [CrossRef]

64. Fu, T.; Jiang, Y.; Lv, J.; Li, Z. Effect of carbon support on Fischer-Tropsch synthesis activity and product distribution over Co-based catalysts. Fuel Process. Technol. 2013, 110, 141-149. [CrossRef]

65. Li, Y.; Wang, T.; Wu, C.; Li, H.; Qin, X.; Tsubaki, N. Gasoline-range hydrocarbon synthesis over $\mathrm{Co} / \mathrm{SiO}_{2} / \mathrm{HZSM}-5$ catalyst with $\mathrm{CO}_{2}$-containing syngas. Fuel Process. Technol. 2010, 91, 388-393. [CrossRef]

66. Oh, J.; Bae, J.W.; Park, S.; Khanna, P.K.; Jun, K. Slurry-Phase Fischer-Tropsch Synthesis Using $\mathrm{Co} / \gamma-\mathrm{Al}_{2} \mathrm{O}_{3}$, $\mathrm{Co} / \mathrm{SiO}_{2}$ and $\mathrm{Co} / \mathrm{TiO}_{2}$ : Effect of Support on Catalyst Aggregation. Catal. Lett. 2009, 130, 403-409. [CrossRef]

67. Soares, R.R.; Frydman, A.; Schmal, M. Effect of preparation method on $5 \% \mathrm{Co} / \mathrm{Nb}_{2} \mathrm{O}_{5}$ in Fischer-Tropsch Syntesis (FTS). Catal. Today 1993, 16, 361-370. [CrossRef]

68. Bertella, F.; Concepción, P.; Martínez, A. TiO 2 polymorph dependent SMSI effect in $\mathrm{Co}-\mathrm{Ru} / \mathrm{TiO}_{2}$ catalysts and its relevance to Fischer-Tropsch synthesis. Catal. Today 2017, 289, 181-191. [CrossRef]

69. Jung, J.; Lee, J.; Choi, G.; Ramesh, S.; Moon, D.J. The characterization of micro-structure of cobalt on $\gamma-\mathrm{Al}_{2} \mathrm{O}_{3}$ for FTS: Effects of pretreatment on $\mathrm{Ru}-\mathrm{Co} / \gamma-\mathrm{Al}_{2} \mathrm{O}_{3}$. Fuel 2015, 149, 118-129. [CrossRef]

70. Jung, J.S.; Choi, G.; Lee, J.S.; Moon, D.J. Microstructure of FTS studies over spherical $\mathrm{Co} / \gamma-\mathrm{Al}_{2} \mathrm{O}_{3}$. Catal. Today 2015, 250, 102-114. [CrossRef]

71. Kim, N.Y.; Jung, J.; Lee, J.S.; Yang, E.H.; Hong, G.H.; Lim, S.S.; Noh, Y.S.; Hodala, J.L.; Lee, K.Y.; Moon, D.J. Synthesis and characterization of Al-modified SBA-15 for Fischer-Tropsch synthesis (FTS) reaction. Res. Chem. Int. 2016, 42, 319-334. [CrossRef]

72. Sun, B.; Yu, G.; Lin, J.; Xu, K.; Pei, Y.; Yan, S.; Qiao, M.; Fan, K.; Zhang, X.; Zong, B. A highly selective Raney Fe@HZSM-5 Fischer-Tropsch synthesis catalyst for gasoline production: One-pot synthesis and unexpected effect of zeolites. Catal. Sci. Technol. 2012, 2, 1625. [CrossRef]

73. Bao, J.; Yang, G.; Okada, C.; Yoneyama, Y.; Tsubaki, N. H-type zeolite coated iron-based multiple-functional catalyst for direct synthesis of middle isoparaffins from syngas. Appl. Catal. A Gen. 2011, 394, 195-200. [CrossRef]

74. Yang, G.; He, J.; Yoneyama, Y.; Tan, Y.; Han, Y.; Tsubaki, N. Preparation, characterization and reaction performance of H-ZSM-5/cobalt/silica capsule catalysts with different sizes for direct synthesis of isoparaffins. Appl. Catal. A Gen. 2007, 329, 99-105. [CrossRef]

75. Yang, G.; He, J.; Zhang, Y.; Yoneyama, Y.; Tan, Y.; Han, Y.; Vitidsant, T.; Tsubaki, N. Design and Modification of Zeolite Capsule Catalyst, A Confined Reaction Field, and its Application in One-Step Isoparaffin Synthesis from Syngas. Energy Fuels 2008, 22, 1463-1468. [CrossRef]

76. Yang, G.; He, J.; Yoneyama, Y.; Tan, Y.; Han, Y.; Tsubaki, N. Design of a zeolite capsule catalyst by controlling the support size for the direct synthesis of isoparaffin. Res. Chem. Intermed. 2008, 34, 771-779. [CrossRef]

77. Calderone, V.R.; Shiju, N.R.; Curulla-Ferré, D.; Chambrey, S.; Khodakov, A.; Rose, A.; Thiessen, J.; Jess, A.; Rothenberg, G. De Novo Design of Nanostructured Iron-Cobalt Fischer-Tropsch Catalysts. Angew. Chem. Int. Ed. 2013, 52, 4397-4401. [CrossRef]

78. Jin, Y.; Yang, R.; Mori, Y.; Sun, J.; Taguchi, A.; Yoneyama, Y.; Abe, T.; Tsubaki, N. Preparation and performance of Co based capsule catalyst with the zeolite shell sputtered by Pd for direct isoparaffin synthesis from syngas. Appl. Catal. A Gen. 2013, 456, 75-81. [CrossRef]

79. Xie, R.; Li, D.; Hou, B.; Wang, J.; Jia, L.; Sun, Y. Silylated $\mathrm{Co}_{3} \mathrm{O}_{4}-\mathrm{m}-\mathrm{SiO}_{2}$ catalysts for Fischer-Tropsch synthesis. Catal. Commun. 2011, 12, 589-592. [CrossRef]

80. Haghtalab, A.; Mosayebi, A. Co@Ru nanoparticle with core-shell structure supported over $\gamma-\mathrm{Al}_{2} \mathrm{O}_{3}$ for Fischer-Tropsch synthesis. Int. J. Hydrogen Energy 2014, 39, 18882-18893. [CrossRef]

81. Lin, Q.; Zhang, Q.; Yang, G.; Chen, Q.; Li, J.; Wei, Q.; Tan, Y.; Wan, H.; Tsubaki, N. Insights into the promotional roles of palladium in structure and performance of cobalt-based zeolite capsule catalyst for direct synthesis of $C_{5}-C_{11}$ iso-paraffins from syngas. J. Catal. 2016, 344, 378-388. [CrossRef] 
82. Yang, G.; Tan, Y.; Han, Y.; Qiu, J.; Tsubaki, N. Increasing the shell thickness by controlling the core size of zeolite capsule catalyst: Application in iso-paraffin direct synthesis. Catal. Commun. 2008, 9, 2520-2524. [CrossRef]

83. XU, K.; CHENG, Y.; SUN, B.; PEI, Y.; YAN, S.R.; QIAO, M.H.; ZHANG, X.X.; ZONG, B.N. Fischer-Tropsch Synthesis over Skeletal Co@HZSM-5 Core-Shell Catalysts. Acta Phys. Chim. Sin. 2015, 31, 1137-1144. [CrossRef]

84. Mosayebi, A.; Haghtalab, A. The comprehensive kinetic modeling of the Fischer-Tropsch synthesis over $\mathrm{Co} @ \mathrm{Ru} / \gamma-\mathrm{Al}_{2} \mathrm{O}_{3}$ core-shell structure catalyst. Chem. Eng. J. 2015, 259, 191. [CrossRef]

85. Parlett, C.M.A.; Wilson, K.; Lee, A.F. Hierarchical porous materials: Catalytic applications. Chem. Soc. Rev. 2013, 42, 3876-3893. [CrossRef] [PubMed]

86. Bezemer, G.L.; Bitter, J.H.; Kuipers, H.P.C.E.; Oosterbeek, H.; Holewijn, J.E.; Xu, X.; Kapteijn, F.; van Dillen, A.J.; de Jong, K.P. Cobalt Particle Size Effects in the Fischer-Tropsch Reaction Studied with Carbon Nanofiber Supported Catalysts. J. Am. Chem. Soc. 2006, 128, 3956-3964. [CrossRef] [PubMed]

87. Liu, J.X.; Wang, P.; Xu, W.; Hensen, E.J. Particle Size and Crystal Phase Effects in Fischer-Tropsch Catalysts. Engineering 2017, 3, 467-476. [CrossRef]

88. Chen, W.; Lin, T.; Dai, Y.; An, Y.; Yu, F.; Zhong, L.; Li, S.; Sun, Y. Recent advances in the investigation of nanoeffects of Fischer-Tropsch catalysts. Catal. Today 2018, 311, 8-22. [CrossRef]

89. Parlett, C.M.A.; Bruce, D.W.; Hondow, N.S.; Lee, A.F.; Wilson, K. Support-Enhanced Selective Aerobic Alcohol Oxidation over Pd/Mesoporous Silicas. ACS Catal. 2011, 1, 636-640. [CrossRef]

90. Xiong, H.; Jewell, L.L.; Coville, N.J. Shaped Carbons As Supports for the Catalytic Conversion of Syngas to Clean Fuels. ACS Catal. 2015, 5, 2640-2658. [CrossRef]

91. Motchelaho, M.A.M.; Xiong, H.; Moyo, M.; Jewell, L.L.; Coville, N.J. Effect of acid treatment on the surface of multiwalled carbon nanotubes prepared from $\mathrm{Fe}-\mathrm{Co}$ supported on $\mathrm{CaCO}_{3}$ : Correlation with Fischer-Tropsch catalyst activity. J. Mol. Catal. A Chem. 2011, 335, 189-198. [CrossRef]

92. Elbashir, N.O.; Bukur, D.B.; Durham, E.; Roberts, C.B. Advancement of Fischer-Tropsch synthesis via utilization of supercritical fluid reaction media. AIChE J. 2010, 56, 997-1015. [CrossRef]

93. Fan, L.; Fujimoto, K. Fischer-Tropsch synthesis in supercritical fluid: Characteristics and application. Appl. Catal. A Gen. 1999, 186, 343-354. [CrossRef]

94. Méndez, C.I.; Ancheyta, J.; Trejo, F. Modeling of Catalytic Fixed-Bed Reactors for Fuels Production by Fischer-Tropsch Synthesis. Energy Fuels 2017, 31, 13011-13042. [CrossRef]

95. Park, J.; Lee, Y.; Jun, K.; Bae, J.W.; Viswanadham, N.; Kim, Y.H. Direct conversion of synthesis gas to light olefins using dual bed reactor. J. Ind. Eng. Chem. 2009, 15, 847-853. [CrossRef]

96. Kang, S.H.; Bae, J.W.; Prasad, P.S.; Jun, K.W. Fischer-Tropsch Synthesis Using Zeolite-supported Iron Catalysts for the Production of Light Hydrocarbons. Catal. Lett. 2008, 125, 264-270. [CrossRef]

97. Kang, S.H.; Bae, J.W.; Woo, K.J.; Prasad, P.S.; Jun, K.W. ZSM-5 supported iron catalysts for Fischer-Tropsch production of light olefin. Fuel Process. Technol. 2010, 91, 399-403. [CrossRef]

98. Cheon, J.; Kang, S.; Bae, J.; Park, S.; Jun, K.; Murali Dhar, G.; Lee, K. Effect of Active Component Contents to Catalytic Performance on Fe-Cu-K/ZSM5 Fischer-Tropsch Catalyst. Catal. Lett. 2010, 134, 233-241. [CrossRef]

99. Bae, J.W.; Park, S.; Kang, S.; Lee, Y.; Jun, K.; Rhee, Y. Effect of Cu content on the bifunctional Fischer-Tropsch $\mathrm{Fe}-\mathrm{Cu}-\mathrm{K} / \mathrm{ZSM} 5$ catalyst. J. Ind. Eng. Chem. 2009, 15, 798-802. [CrossRef]

100. Kim, J.H.; Kim, H.S.; Oh, S.C.; Ryu, J.H.; Kang, S.H. Catalyst for Synthesizing Synthetic Natural Gas and Manufacturing Method for High Calorific Synthetic Natural Gas Using the Same. Korea Patent No. 10-2017-0181241, 17 December 2017.

101. Kim, J.H.; Kim, H.S.; Ryu, J.H.; Kang, S.H.; Lee, S.C.; Chae, H.J.; Jo, S.B.; Kim, T.Y. Method for Preparing Synthetic Natural Gas Using Co-Fe-Ni-based Catalyst. Korea Patent No. 10-2018-0169727, 26 December 2018.

102. Kang, S.H.; Ryu, J.H.; Kim, J.H.; Seo, S.J.; Yoo, Y.D.; Prasad, P.S.S.; Lim, H.J.; Byun, C.D. Co-methanation of $\mathrm{CO}$ and $\mathrm{CO}_{2}$ on the $\mathrm{Ni}_{X}-\mathrm{Fe}_{1-X} / \mathrm{Al}_{2} \mathrm{O}_{3}$ catalysts; effect of Fe contents. Korean J. Chem. Eng. 2011, 28, 2282-2286. [CrossRef]

103. Lee, Y.; Lee, K. Effect of surface composition of Fe catalyst on the activity for the production of high-calorie synthetic natural gas (SNG). Korean J. Chem. Eng. 2017, 34, 320-327. [CrossRef]

104. Jo, S.B.; Chae, H.J.; Kim, T.Y.; Kim, J.W.; Kim, J.C.; Lee, S.C.; Lee, C.H.; Oh, J.U.; Kang, S.; Jeong, M. Selective $\mathrm{CO}$ hydrogenation over bimetallic Co-Fe catalysts for the production of light paraffin hydrocarbons $\left(\mathrm{C}_{2}-\mathrm{C}_{4}\right)$ : Effect of $\mathrm{H}_{2} / \mathrm{CO}$ ratio and reaction temperature. Catal. Commun. 2018, 117, 74-78. [CrossRef] 
105. Jo, S.B.; Kim, T.Y.; Lee, C.H.; Woo, J.H.; Chae, H.J.; Kang, S.; Kim, J.W.; Lee, S.C.; Kim, J.C. Selective CO Hydrogenation Over Bimetallic Co-Fe Catalysts for the Production of Light Paraffin Hydrocarbons $\left(C_{2}-C_{4}\right)$ : Effect of Space Velocity, Reaction Pressure and Temperature. Catalysts 2019, 9, 779. [CrossRef]

106. Bukur, D.B.; Lang, X.; Nowicki, L. Comparative Study of an Iron Fischer-Tropsch Catalyst Performance in Stirred Tank Slurry and Fixed-Bed Reactors. Ind. Eng. Chem. Res. 2005, 44, 6038-6044. [CrossRef]

107. Kang, S.; Woo, K.; Jun, K.; Kang, Y. Hydrogenation of $\mathrm{CO}$ on supported cobalt $\gamma-\mathrm{Al}_{2} \mathrm{O}_{3}$ catalyst in fixed bed and slurry bubble column reactors. Korean J. Chem. Eng. 2009, 26, 1533-1538. [CrossRef]

108. Kamm, B.; Kamm, M. Das Konzept der Bioraffinerie-Produktion von Plattformchemikalien und Finalprodukten. Chem. Ing. Tech. 2007, 79, 592-603. [CrossRef]

109. Rahimpour, M.R.; Elekaei, H. A comparative study of combination of Fischer-Tropsch synthesis reactors with hydrogen-permselective membrane in GTL technology. Fuel Process. Technol. 2009, 90, 747-761. [CrossRef]

110. Lee, Y.; Park, J.; Jun, K.; Bae, J.; Viswanadham, N. Enhanced Production of $\mathrm{C}_{2}-\mathrm{C}_{4}$ Olefins Directly from Synthesis Gas. Catal. Lett. 2008, 126, 149-154. [CrossRef]

111. Kang, S.; Bae, J.W.; Cheon, J.; Lee, Y.; Lee, D.; Ha, K.; Jun, K.; Kim, B. Catalytic performance on iron-based Fischer-Tropsch catalyst in fixed-bed and bubbling fluidized-bed reactor. Appl. Catal. B Environ. 2011, 103, 169-180. [CrossRef]

112. Hong, J.; Hwang, J.S.; Jun, K.; Sur, J.C.; Lee, K. Deactivation study on a coprecipitated Fe-Cu-K-Al catalyst in $\mathrm{CO}_{2}$ hydrogenation. Appl. Catal. A Gen. 2001, 218, 53-59. [CrossRef]

113. Jun, K.; Roh, H.; Kim, K.; Ryu, J.; Lee, K. Catalytic investigation for Fischer-Tropsch synthesis from bio-mass derived syngas. Appl. Catal. A Gen. 2004, 259, 221-226. [CrossRef]

114. Kang, S.; Bae, J.W.; Sai Prasad, P.S.; Park, S.; Woo, K.; Jun, K. Effect of Preparation Method of Fe-based Fischer-Tropsch Catalyst on their Light Olefin Production. Catal. Lett. 2009, 130, 630-636. [CrossRef]

115. Kang, S.; Koo, H.M.; Kim, A.R.; Lee, D.; Ryu, J.; Yoo, Y.D.; Bae, J.W. Correlation of the amount of carbonaceous species with catalytic performance on iron-based Fischer-Tropsch catalysts. Fuel Process. Technol. 2013, 109, 141-149. [CrossRef]

116. Kang, S.; Ryu, J.; Kim, J.; Sai Prasad, P.; Bae, J.; Cheon, J.; Jun, K. ZSM-5 Supported Cobalt Catalyst for the Direct Production of Gasoline Range Hydrocarbons by Fischer-Tropsch Synthesis. Catal. Lett. 2011, 141, 1464-1471. [CrossRef]

117. Kang, S.; Ryu, J.; Kim, J.; Jang, I.H.; Kim, A.R.; Han, G.Y.; Bae, J.W.; Ha, K. Role of ZSM5 Distribution on $\mathrm{Co} / \mathrm{SiO}_{2}$ Fischer-Tropsch Catalyst for the Production of $\mathrm{C}_{5}-\mathrm{C}_{22}$ Hydrocarbons. Energy Fuels 2012, 26, 6061-6069. [CrossRef]

118. Kang, S.; Ryu, J.; Kim, J.; Kim, H.; Lee, C.; Lee, Y.; Jun, K. Fischer-Tropsch Synthesis of the Promoted Co/ZSM-5 Hybrid Catalysts for the Production of Gasoline Range Hydrocarbons. Mod. Res. Catal. 2014, 3, 99-106. [CrossRef]

119. Ryu, J.; Kang, S.; Kim, J.; Lee, Y.; Jun, K. Fischer-Tropsch synthesis on Co- $\mathrm{Al}_{2} \mathrm{O}_{3}$-(promoter)/ZSM5 hybrid catalysts for the production of gasoline range hydrocarbons. Korean J. Chem. Eng. 2015, 32, 1993-1998. [CrossRef]

120. Kang, S.; Ryu, J.; Kim, J.; Kim, H.; Yang, H.C.; Chung, D.Y. Catalytic Performance for Hydrocarbon Production from Syngas on the Promoted Co-Based Hybrid Catalysts; Influence of Pt Contents. Bull. Chem. React. Eng. Catal. 2017, 12, 452-459. [CrossRef]

121. Cho, J.M.; Lee, S.R.; Sun, J.; Tsubaki, N.; Jang, E.J.; Bae, J.W. Highly Ordered Mesoporous $\mathrm{Fe}_{2} \mathrm{O}_{3}-\mathrm{ZrO}_{2}$ Bimetal Oxides for an Enhanced CO Hydrogenation Activity to Hydrocarbons with Their Structural Stability. ACS Catal. 2017, 7, 5955-5964. [CrossRef]

122. Cho, J.M.; Han, G.Y.; Jeong, H.; Roh, H.; Bae, J.W. Effects of ordered mesoporous bimodal structures of Fe/KIT-6 for CO hydrogenation activity to hydrocarbons. Chem. Eng. J. 2018, 354, 197-207. [CrossRef]

123. Park, Y.M.; Lee, D.H.; Lee, Y.J.; Roh, H.S.; Chung, C.H.; Wook Bae, J. Ordered Mesoporous $\mathrm{Co}_{3} \mathrm{O}_{4}-\mathrm{Al}_{2} \mathrm{O}_{3}$ Binary Metal Oxides for CO Hydrogenation to Hydrocarbons: Synergy Effects of Phosphorus Modifier for an Enhanced Catalytic Activity and Stability. ChemCatChem 2019, 11, 1707-1721. [CrossRef]

124. Cho, J.M.; Kasipandi, S.; Park, Y.M.; Bae, J.W. Spatially confined cobalt nanoparticles on zirconium phosphate-modified KIT-6 for an enhanced stability of CO hydrogenation to hydrocarbons. Fuel 2019, 239, 547-558. [CrossRef] 
125. Choi, S.; Xie, S.; Shao, M.; Odell, J.H.; Lu, N.; Peng, H.; Protsailo, L.; Guerrero, S.; Park, J.; Xia, X.; et al. Synthesis and characterization of $9 \mathrm{~nm}$ Pt-Ni octahedra with a record high activity of $3.3 \mathrm{~A} / \mathrm{mg}(\mathrm{Pt})$ for the oxygen reduction reaction. Nano Lett. 2013, 13, 3420-3425. [CrossRef] [PubMed]

126. Park, J.; Kanti Kabiraz, M.; Kwon, H.; Park, S.; Baik, H.; Choi, S.; Lee, K. Radially Phase Segregated PtCu@PtCuNi Dendrite@Frame Nanocatalyst for the Oxygen Reduction Reaction. ACS Nano 2017, 11, 10844-10851. [CrossRef] [PubMed]

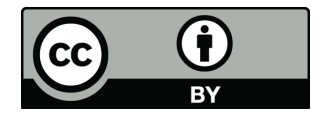

(C) 2020 by the authors. Licensee MDPI, Basel, Switzerland. This article is an open access article distributed under the terms and conditions of the Creative Commons Attribution (CC BY) license (http://creativecommons.org/licenses/by/4.0/). 